\title{
Hydrophobic but Water-Friendly: Favorable Water-Perfluoromethyl Interactions Promote Hydration Shell Defects
}

\author{
João R. Robalo, ${ }^{\dagger}$ Louis M. Streacker, ${ }^{\ddagger}$ Denilson Mendes de Oliveira, ${ }^{\ddagger}$ Petra Imhof, ${ }^{\S}, \| \odot$ \\ Dor Ben-Amotz, ${ }^{\ddagger}$ and Ana Vila Verde* $* \oplus \bullet$ \\ ${ }^{\dagger}$ Department of Theory \& Bio-systems, Max Planck Institute for Colloids and Interfaces, Science Park, Potsdam 14476, Germany \\ ${ }^{\ddagger}$ Department of Chemistry, Purdue University, West Lafayette, Indiana 47907, United States \\ ${ }^{\S}$ Institute for Theoretical Physics, Free University of Berlin, Arnimallee 14, 14195 Berlin, Germany
}

Supporting Information

\begin{abstract}
Although perfluorination is known to enhance hydrophobicity and change protein activity, its influence on hydration-shell structure and thermodynamics remains an open question. Here we address that question by combining experimental Raman multivariate curve resolution spectroscopy with theoretical classical simulations and quantum mechanical calculations. Perfluorination of the terminal methyl group of ethanol is found to enhance the disruption of its hydration-shell hydrogen bond network. Our results reveal that this disruption is not due to the associated volume change but rather to the electrostatic stabilization of the water dangling $\mathrm{OH} \cdots \mathrm{F}$ interaction. Thus, the hydration shell structure of fluorinated methyl groups results from a delicate balance of solute-water interactions that is intrinsically different from that associated with a methyl group.
\end{abstract}

\section{INTRODUCTION}

The perfluorination of hydrocarbons or alkyl substituents often increases their hydrophobicity as evidenced, for example, by the decreased solubility of methane $\left(\mathrm{CH}_{4}\right)$ upon fluorination (to $\left.\mathrm{CF}_{4}\right)^{1}$ and the increased aqueous contact angle of polyethylene (PE) upon fluorination (to PTFE). ${ }^{2}$ Moreover, the introduction of short, perfluorinated alkyl groups in biomolecules strongly affects their thermodynamic, kinetic, and binding properties. ${ }^{3-17}$ This power is reflected in the many drug and agrochemical candidates with perfluoroalkyl substituents that now exist. ${ }^{18-21}$ Predictively understanding the influence of fluorination on such aqueous processes requires quantifying the associated solute-water interactions, as those interactions determine hydration free energies and thus also the influence of water on folding and binding processes. ${ }^{22}$ Although previous infrared spectroscopic studies have provided intriguing hints regarding the influence of fluorination on hydration, ${ }^{23,24}$ they have not quantified the associated changes in hydration-shell structure and thermodynamics. Here we do so by combining Raman multivariate curve resolution (Raman-MCR) spectroscopy with classical molecular dynamics (MD) simulations and ab initio interaction energy calculations. Our Raman-MCR spectra reveal striking differences between the hydration-shell structures of ethanol (EtOH) and 2,2,2-trifluoroethanol (TFE) dissolved in water. Comparisons of those experimental results with molecular dynamics simulation predictions obtained using classical force fields facilitate the definitive assignment of the observed fluorination-induced hydration-shell structure changes, quanti- tatively link those changes to hydration thermodynamics, and establish the electrostatic origin of these changes.

Perfluorination is known to influence solute-water interactions, but it is clear that open questions remain. Perfluoroalkanes ( $\mathrm{C} 1$ to $\mathrm{C} 3$; with 1 to 3 carbons) have less favorable hydration free energies $\left(\Delta G_{\mathrm{Hyd}}\right)$ than the analogous alkanes. ${ }^{1,25-28}$ Whereas the hydration free energies of C1-toC3 alkanes are essentially identical despite increasing volume, those of the analogous perfluoroalkanes become more positive with growing number of carbons, suggesting that perfluorination may decrease solute-water attraction. However, differences in hydration free energy between large (C8) alkanes and perfluoroalkanes from simulation have been attributed primarily to the different volume of these molecules (rather than a decrease in solute-water attraction), ${ }^{29}$ suggesting that perfluorination may increase repulsive (entropic) excludedvolume contributions to hydration. In either case, because aggregation would be expected to decrease both solventaccessibility and excluded volume one might have guessed that perfluorination would lead to increased aggregation: for a solute aggregation process, the water-mediated contribution to the solute-solute interaction potential is equal to the difference between the hydration free energy of the aggregate and the (sum of the) hydration free energies of the solutes at infinite dilution. However, molecular balance experiments indicate that the solvent-mediated component of the

Received: June 28, 2019

Published: September 10, 2019 
interaction potential between perfluoro (C6) substituents is indistinguishable from that between the analogous alkyl groups; ${ }^{30}$ the entropy contribution to the free energy of binding of benzensulfonamide ligands with alkyl or fluoroalkyl (C2 to C5) tails to carbonic anhydrases, measured using isothermal titration calorimetry, is only partially explained by the different area of the ligand tails; ${ }^{13}$ replacing $-\mathrm{CH}_{3}$ by $-\mathrm{CF}_{3}$ in the side chain of an amino acid at the binding site of the protein BPTI dramatically increases binding to $\beta$-trypsin. ${ }^{14}$

The above results suggest that the hydration shell of small alkyl and perfluoroalkyl groups should differ, but no previous experimentally grounded comparisons have been performed to critically detect and quantify such differences. We have found that the population of non-hydrogen-bonded ("dangling") water hydroxy $(\mathrm{OH})$ groups at the water-hydrophobe interface, transient hydration shell defects, provides a sensitive means of quantifying and understanding how perfluorination alters hydration-shell structure and thermodynamics. Prior studies have reported the presence of such dangling $\mathrm{OH}$ structures, detectable as a vibrational peak near 3600 $\mathrm{cm}^{-1},{ }^{31-38}$ both at macroscopic and molecular hydrophobic interfaces. At macroscopic air-water and oil-water interfaces, experiments and simulations suggest that $20 \%-30 \%$ of the interfacial water molecules have one dangling hydroxy. ${ }^{31,32,36,37,39-45}$ In molecular hydrophobic hydration shells, the dangling $\mathrm{OH}$ structures have about a 10 times lower probability (per first hydration-shell water molecule) ${ }^{46}$ but increase with increasing $n$-alcohol chain-length ${ }^{34}$ and with increasing solute negative partial charge. ${ }^{34,47}$ In this work, we present both experimental and theoretical results revealing the marked increase in the hydration-shell dangling $\mathrm{OH}$ population upon perfluorination of ethanol's methyl group. We further show that this increased population does not result from the larger volume of $-\mathrm{CF}_{3}$ relative to $-\mathrm{CH}_{3}$ but rather is due to the negative partial charge of the $\mathrm{F}$ atoms, which electrostatically stabilize the hydration-shell dangling $\mathrm{OH}$ structures. Moreover, we find that the dangling $\mathrm{OH}$ groups in the hydration shells of $-\mathrm{CF}_{3}$ and $-\mathrm{CH}_{3}$ have virtually identical frequencies, thus indicating that the associated interaction is exceptionally weak, as further confirmed and quantified by experimental and theoretical comparisons of the $-\mathrm{CF}_{3} \cdots \mathrm{HO}-$ and $-\mathrm{CH}_{3} \cdots \mathrm{HO}-$ interaction enthalpies and entropies. Our results indicate that the mechanism behind the formation of dangling $\mathrm{OH}$ structures is inherently different for EtOH and TFE, which suggests that not only are $-\mathrm{CF}_{3}$ and $-\mathrm{CH}_{3}$ chemically different but also they are intrinsically different with regards to their hydrophobicity.

\section{METHODS}

Experimental Methods. All aqueous solutions were prepared using ultrapurified water (18.2 $\mathrm{M} \Omega \mathrm{cm}$ resistivity, Milli-Q UF Plus). Ethanol (200 proof, anhydrous, Decon Laboratories, Inc.) was used without further purification, and 2,2,2-trifluoroethanol $(99.5+\%$, Sigma-Aldrich) was used after distillation. In view of the toxicity of the fluorinated alcohols, solutions were prepared in a fume hood and enclosed in O-ring-sealed glass vials for Raman spectroscopic analysis.

The custom-built micro-Raman system has been previously described. $^{48,49}$ Briefly, it consists of a $514.5 \mathrm{~nm}$ Argon-ion laser (Melles-Griot 43 Series) with $\sim 20 \mathrm{~mW}$ of power at the sample contained in a $1 \mathrm{~cm}$ spectroscopic glass cell and mounted in a temperature-controlled sample stage (LC-600, Quantum Northwest). A long-working distance $20 \times$ (Mitutoyo Inc.) objective is used to focus the laser into the center of the glass cell and collect the backscattered Raman light, which is subsequently focused using an $f=$
$50 \mathrm{~mm}$ achromatic lens onto a $7 \times 100 \mu \mathrm{m}$ core (6-around-1) fiber optic bundle (LEONI Fiber Optics, Inc.). The other end of the bundle, whose fibers are arranged in a linear stack, are coupled to the entrance slit of a $300 \mathrm{~mm}$ focal length imaging spectrograph (SpectraPro300i, Acton Research Inc.), equipped with a $300 \mathrm{gr} / \mathrm{mm}$ grating, and a thermoelectrically cooled CCD camera (Princeton Instruments Inc., Pixis $400,1340 \times 400$ pixel). Duplicate 5 min spectra were acquired for all samples to produce Raman spectra with a signal-to-noise ratio of $\sim 10000: 1$ at the water $\mathrm{OH}$ band maximum. Self-modeling curve resolution (SMCR) ${ }^{50}$ was used to obtain solutecorrelated (SC) spectra from pure water and solution spectra.

The thermodynamic analyses of the high-frequency $\mathrm{OH}$ hydrationshell structure were extracted using a method similar to that previously used to quantify the high-frequency water structure around $\mathrm{CO}_{2}{ }^{47}$ and dangling-OH structures in the hydration shells of nonpolar groups. ${ }^{34}$ Specifically, to obtain the Gibbs free energy $(\Delta G)$, enthalpy $(\Delta H)$, and entropy $(\Delta S)$, SMCR was used to find the nonnegative minimum area spectrum for the high-frequency $\mathrm{SC}$ water feature, and then the pure solvent spectrum was further subtracted from the SC spectrum, so as to obtain the high-frequency feature that has a near-zero baseline on either side of the peak (as was done to obtain SI Figure S7 in ref 47). First, the ratio of the Raman cross section for solute $\mathrm{CH}$ groups and water $\mathrm{OH}$ groups $\left(\Omega_{\mathrm{CH}} / \Omega_{\mathrm{OH}}\right)$ is calculated for each solution and temperature as follows: ${ }^{49}$

$$
\frac{\Omega_{\mathrm{CH}}}{\Omega_{\mathrm{OH}}}=\left(\frac{I_{\mathrm{CH}}^{\mathrm{S}}}{I_{\mathrm{OH}}^{\mathrm{W}}}\right)\left(\frac{2[\mathrm{~W}]}{n_{\mathrm{CH}}[\mathrm{S}]}\right)
$$

Here, $I_{\mathrm{CH}}^{\mathrm{S}}$ is the area of the $\mathrm{C}-\mathrm{H}$ stretch band of the solute, $I_{\mathrm{OH}}^{\mathrm{W}}$ the area of the $\mathrm{O}-\mathrm{H}$ stretch band in the pure water, $2[\mathrm{~W}] \sim 2 \times 55.5 \mathrm{~mol}$ $\mathrm{dm}^{-3}=111 \mathrm{~mol} \mathrm{dm}$ the concentration of $\mathrm{OH}$ bonds in water, $n_{\mathrm{CH}}$ the number of $\mathrm{C}-\mathrm{H}$ bonds per solute, and $[\mathrm{S}]$ the concentration of solute. Thus, the average number of dangling $\mathrm{OH}$ structures per hydration shell $\langle k\rangle$ is obtained using eq 2 , as previously described. ${ }^{34}$

$$
\langle k\rangle=n_{\mathrm{CH}}\left(f \frac{\Omega_{\mathrm{CH}}}{\Omega_{\mathrm{OH}}}\right)\left(\frac{I_{\mathrm{OH}}}{I_{\mathrm{CH}}}\right)_{\text {dangling }}
$$

In eq $2, f$ represents a factor that can account for a difference between the Raman cross sections of hydrogen-bonded and non-hydrogen bonded $\mathrm{OH}$ groups (as discussed in Experimental Results). The intensity ratio $\left(\frac{I_{\mathrm{OH}}}{I_{\mathrm{CH}}}\right)_{\text {dangling }}$ represents the area of the dangling $\mathrm{OH}$ band after normalization to the solute $\mathrm{CH}$ band area. When the probability that each hydration-shell water molecule forms a dangling $\mathrm{OH}$ defect is treated using a lattice model, the quantity $\langle k\rangle$ is predicted to be approximately equal to the equilibrium constant constant, $K$, pertaining to the transformation of a hydration shell with no dangling $\mathrm{OH}$ defects to one that contains a single such defect (as previously described). ${ }^{34}$ Thus, the following expressions may be used to obtain the thermodynamics parameters associated with the formation of a high-frequency dangling $\mathrm{OH}$ structure in the hydration shell of the solute:

$$
\begin{aligned}
& \Delta G=-R T \ln \langle k\rangle \\
& \Delta H=\left[\frac{\partial(\Delta G / T)}{\partial(1 / T)}\right]_{P} \\
& \Delta S=-\left(\frac{\partial \Delta G}{\partial T}\right)_{P}
\end{aligned}
$$

where $R$ is the ideal gas constant and $T$ is temperature.

Molecular Dynamics with Classical Force Fields. The water model used in this work is TIP4P-Ew. ${ }^{51}$ In this model, hydrogen atoms have a charge $q_{\mathrm{H}}=+0.52422 e$ and Lennard-Jones (LJ) parameters set to zero; oxygen has no charge and LJ parameters $\varepsilon_{\mathrm{OO}}=$ $0.680946 \mathrm{~kJ} \mathrm{~mol}^{-1}$ and $\sigma_{\mathrm{OO}}=3.16435 \AA$; a negative charge of magnitude $q_{\mathrm{M}}=-1.04844 e$ is located along the direction bisecting the region between the two hydrogens, $0.1250 \AA$ from the oxygen atom. 
Ethanol was modeled using three different force fields: OPLS, ${ }^{52}$ $\mathrm{GAFF}^{53}$ and a variant of GAFF denoted as $\mathrm{GAFF}_{\mathrm{H}}$ where the LJ $\varepsilon$ parameter of nonpolar hydrogen atoms was optimized against the hydration free energy of ethane (see SI section 2) and the remaining LJ parameters are from GAFF. 2,2,2-Trifluoroethanol was modeled using 4 different force fields: the Vymertal ${ }^{54}$ force field, the Gerig ${ }^{55}$ force field and two variants of GAFF denoted as TFE-Robalo and TFE-Robalo $\mathrm{H}_{\mathrm{H}}$. The TFE-Robalo variant differs from GAFF only in its $\mathrm{LJ}$ fluorine parameters, which are those reported in ref 56; the TFERobalo $_{\mathrm{H}}$ variant differs from GAFF in both its $\mathrm{LJ}$ fluorine parameters (also from ref 56) and its nonpolar hydrogen atoms, which are the same as those used in EtOH-GAFF ${ }_{\mathrm{H}}$. For all GAFF-based force fields, charges were calculated using the $\mathrm{RESP}^{57}$ procedure at the RHF/6$31 \mathrm{G}^{*}$ level of theory (following two sequential geometry optimizations at the MP2 and then RHF level of theory using the 6-31G* basis set), with the ESP surface evaluated at roughly 50 points per atom in four layers corresponding to a scaling of all atomic van der Waals radii of 1.4, 1.6, 1.8, and 2.0. RESP fits were performed with Gaussian $03^{58}$ and Antechamber, ${ }^{59}$ and the conversion of the resulting topology files from AMBER ${ }^{60}$ format into Gromacs ${ }^{61-67}$ format was carried with the ACPYPE ${ }^{68}$ software. Note that models EtOH-GAFF and $\mathrm{EtOH}-\mathrm{GAFF}_{\mathrm{H}}$ have identical charges; the same occurs for models TFE-Robalo and TFE-Robalo ${ }_{\mathrm{H}}$ (Figure S3).

Free energies of hydration were calculated using free energy perturbation (FEP), by progressively decoupling solute-solvent interactions in a cubic simulation box consisting of a single solute molecule surrounded by liquid. The systems were assembled using the built-in tools in Gromacs. First, Coulombic interactions were scaled by a parameter $\lambda_{\mathrm{C}}$, which adopted the value of 0.00 (fully coupled), $0.05,0.10,0.15,0.20,0.25,0.30,0.35,0.40,0.45,0.50,0.55,0.60$, $0.65,0.70,0.75,0.80,0.85,0.90,0.95$, and 1.00 (fully decoupled). Second, with fully decoupled Coulombic interactions, LJ interactions were scaled by a $\lambda_{\mathrm{LJ}}$ parameter, set to 0.00 (fully coupled), $0.03,0.06$, $0.09,0.12,0.15,0.18,0.21,0.24,0.27,0.30,0.33,0.36,0.39,0.42$, $0.44,0.46,0.48,0.50,0.51,0.52,0.53,0.54,0.55,0.56,0.57,0.58$, $0.59,0.60,0.61,0.62,0.63,0.64,0.65,0.66,0.67,0.68,0.69,0.70$, $0.71,0.72,0.73,0.74,0.75,0.76,0.77,0.78,0.79,0.80,0.82,0.84$, $0.86,0.88,0.90,0.92,0.94,0.96,0.98$, and 1.00 (fully decoupled), for a total of 80 coulomb- and LJ-decoupling steps. Simulations used a time-step of $2 \mathrm{fs}$, and constraints ( LINCS $^{69}$ ) were applied to all bonds involving hydrogen atoms. Integration of the equations of motion was done using a leapfrog Langevin dynamics algorithm with a collision frequency of $1 \mathrm{ps}^{-1}$ set at the desired temperature $T=298 \mathrm{~K}$. The van der Waals interactions were modeled with a cutoff of $1.2 \mathrm{~nm}$ (and switched to zero between 1.0 and $1.2 \mathrm{~nm}$ ), and long-range dispersion corrections were applied to both pressure and energy. Long-range electrostatics were treated with the $\mathrm{PME}^{70}$ scheme with a $1.2 \mathrm{~nm}$ cutoff, a grid spacing of $0.1 \mathrm{~nm}$, and a fourth-order interpolation. Energies were collected from the individual simulations using the BAR method as implemented in Gromacs. For each value of $\lambda_{\mathrm{C} / \mathrm{L} \mathrm{J}}$, a steepest descent minimization was followed by a L-BFGS minimization, after which 100 ps of NVT equilibration and 100 ps of $N p T$ equilibration took place. The production runs for each $\lambda_{\mathrm{C} / \mathrm{LJ}}$ were 5 ns long. A similar protocol was employed in our previous work $^{56}$ (with shorter, 2 ns production runs) and found to yield converged free energies of hydration for single amino acids in water; the length of the production runs was increased to $5 \mathrm{~ns}$ for even greater accuracy.

To investigate the formation of dangling $\mathrm{OH}$ groups in the hydration shell of EtOH and TFE, the simulation boxes consisted of a single solute molecule surrounded by $\approx 2 \mathrm{~nm}$ of water, assembled using the built-in tools in Gromacs. The dynamics of water molecules-and, therefore, the formation of dangling hydroxy structures in the hydration shell of a solute-can be greatly affected by the use of a thermostat and a barostat. To minimize such effects, our measurements are taken from constant-volume simulations (NVT ensemble, no barostat required) with a weakly coupled thermostat $\left(0.05 \mathrm{ps}^{-1}\right.$ collision frequency for the Langevin dynamics integrator). The initial configurations for the production simulations are extracted from a 2 ns simulation in the constant pressure and temperature ensemble (steepest descent minimization followed by a L-BFGS minimization, after which 100 ps of NVT equilibration and 100 ps of $N p T$ equilibration took place), under the condition that the configuration's volume does not differ by more than $0.5 \AA^{3}$ from the average ensemble volume. Finally, the NVT production run spans $25 \mathrm{~ns}$, with sample collection occurring every $0.1 \mathrm{ps}$. Simulations were performed at $T=(278,298,318,338,358) \mathrm{K}$. All simulations were carried out with Gromacs. Unless otherwise mentioned, the simulation conditions were the same as for the free energy calculations.

The thermodynamics of the formation of dangling hydroxy structures were evaluated for the population of water molecules for which the oxygen atom is within 5.531 or $5.690 \AA$ of the carbon atom in the $-\mathrm{CH}_{3}(\mathrm{EtOH})$ or $-\mathrm{CF}_{3}$ (TFE) group, respectively. These distances correspond to the first minimum of the radial distribution function of water oxygen atoms around the carbon atom in $\mathrm{CH}_{4} / \mathrm{CF}_{4}$ (results not shown). A dangling hydroxy structure is considered to exist if one hydroxy group from this population of water molecules is pointing toward the $-\mathrm{CH}_{3}$ (EtOH) or $-\mathrm{CF}_{3}$ (TFE) group (see Results and Discussion and the Supporting Information for the specific criteria used in identifying dangling hydroxys). Statistics for dangling hydroxy structures were collected using our own scripts running in VMD. ${ }^{71}$

Symmetry-Adapted Perturbation Theory. Dimers consisting of one water molecule and one alcohol molecule (either EtOH or TFE) were collected from MD simulations using the EtOH-GAFF ${ }_{H}$

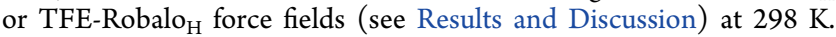
The criteria for collecting a water-alcohol dimer configuration were (i) the water molecule oxygen atom is within $3.5 \AA$ of the $-\mathrm{CH}_{3} /-$ $\mathrm{CF}_{3}$ hydrogen/fluorine atom in the alcohol, i.e., within a distance that allows the water molecule to have a dangling hydroxy group; (ii) the water molecule oxygen atom is beyond $4.5 \AA$ of the carbon atom bound to the alcohol group in EtOH/TFE, so that the only direct interaction between the water molecule and the alcohol molecule occurs at the site of the alcohol's hydrophobic group. Configurations were collected both for water molecules with one dangling hydroxy and water molecules with no dangling hydroxy structures; in either case, the nondangling hydroxy groups were hydrogen-bonded to other water molecules. The number of collected dimer configurations was EtOH, dangling: 938; TFE, dangling: 1314; EtOH, bound: 689; and TFE, bound: 1000 .

For each dimer configuration, a wave function-based symmetryadapted perturbation theory (SAPT; refs 72 and 73 provide a comprehensive review on the topic) calculation was performed to decompose the total interaction energy between water and alcohol into induction, electrostatic, exchange, and dispersion contributions. SAPT calculations were conducted with the Psi4 software ${ }^{74}$ at the DF-SAPT2+(CCD) $\delta \mathrm{MP} 2$ level of theory, employing the augmented, correlation-consistent, triple- $\zeta$ Dunning basis sets (aug-ccpVTZ). ${ }^{75-78}$ This level of theory was found to provide "the most accurate overall model chemistry" in a comparative study of a series of SAPT methodologies. ${ }^{79}$ In short, the interaction energy is treated as a second-order expansion of the intra- and intermolecular potentials. ${ }^{79}$ Dispersion interactions are calculated with coupled-cluster doubles $^{80,81}$ via the natural orbitals formalism; ${ }^{82}$ an MP2 correction is applied to account for high-order induction-dispersion coupling. ${ }^{79}$ The frozen core approximation is used in the treatment of nonvalence electrons, and a density-fitting approximation ${ }^{83,84}$ is employed for two-electron integrals in self-consistent field Hartree-Fock calculations, together with a superposition-of-atomic-densities estimate for the initial density-fitted orbitals.

\section{RESULTS AND DISCUSSION}

Experimental Results. Figure 1 shows Raman spectra and Raman-MCR results obtained from pure water and $1 \mathrm{~mol} \mathrm{dm} \mathrm{dm}^{-3}$ aqueous solutions of ethanol and 2,2,2trifluoroethanol. The measured (unprocessed) Raman spectra of pure water shown in panel A contains peaks arising from the water $\mathrm{OH}$ stretch $\left(\right.$ near $\left.3400 \mathrm{~cm}^{-1}\right)$, bend $\left(\right.$ near $\left.1650 \mathrm{~cm}^{-1}\right)$, 

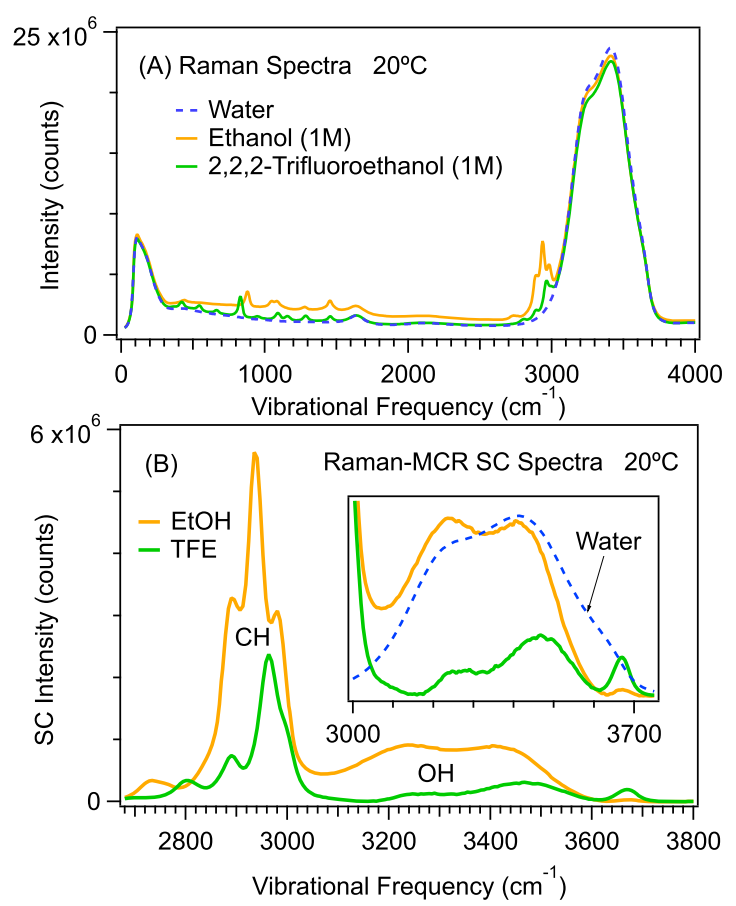

Figure 1. Measured Raman spectra (A) and Raman-MCR SC spectra (B) obtained from water and $1 \mathrm{~mol} \mathrm{dm} \mathrm{dm}^{-3}$ aqueous solutions of ethanol (EtOH) and 2,2,2-trifluoroethanol (TFE). The Raman spectra in panel A are unprocessed (except for subtracting a constant baseline offset). The solid curves spectra in panel B are solutecorrelated (SC) spectra of EtOH and TFE (with their experimental intensities, pertaining to the same $1 \mathrm{~mol} \mathrm{dm}^{-3}$ concentration), and the inset panel shows an expanded view of the $\mathrm{OH}$ stretch region, compared to that of pure water (arbitrarily scaled to the same peak intensity as the $\mathrm{EtOH} \mathrm{SC} \mathrm{OH}$ band).

as well as low-frequency $\mathrm{OH} \cdots \mathrm{O}$ stretch (near $200 \mathrm{~cm}^{-1}$ ), and other low-frequency and collective vibrations and combination bands. ${ }^{85}$ The measured Raman spectra of the aqueous solutions in panel A reveal additional features arising from intramolecular vibrational modes of EtOH and TFE, including the $\mathrm{CH}$ stretch bands (near $2900 \mathrm{~cm}^{-1}$ ). Note that the latter band is larger for EtOH than TFE (although they both have the same concentration) because $\mathrm{EtOH}$ has five $\mathrm{CH}$ groups, while TFE has only two. The EtOH and TFE $\mathrm{CH}$ and hydration-shell $\mathrm{OH}$ spectra shown in panel $\mathrm{B}$ were obtained from a Raman-MCR decomposition of the measured solution spectra into pure water and solute-correlated components. The SC $\mathrm{OH}$ stretch bands arise primarily from hydration-shell water molecules whose vibrational spectra are perturbed by the solute. Clearly these hydration-shell spectra both look significantly different than the $\mathrm{OH}$ stretch band of pure water (the dashed-blue band in the inset panel), and the hydration shell of TFE also looks remarkably different from that of EtOH. More specifically, the larger area of the SC hydration-shell spectrum of EtOH as compared to that of TFE implies that more water molecules are perturbed by $\mathrm{EtOH}$ than by TFE. This is particularly the case in the lowerfrequency portion of the $\mathrm{OH}$ stretch band (near $3200 \mathrm{~cm}^{-1}$ ) corresponding to a shoulder which also becomes more intense in highly tetrahedral ice and clathrate structures. ${ }^{86,87}$ Thus, the fact that the $3200 \mathrm{~cm}^{-1}$ shoulder is relatively more prominent in the hydration shell of EtOH than TFE, as well as in pure water, implies that the hydration shell of $\mathrm{EtOH}$ has a more tetrahedral structure than pure water. On the other hand, the relative low intensity of the $3200 \mathrm{~cm}^{-1}$ shoulder in the TFE hydration shell indicates that these water molecules are less tetrahedral than pure water. Even more interestingly, both the hydration shells of EtOH and TFE contain small highfrequency features (between 3600 and $3700 \mathrm{~cm}^{-1}$ ) associated with dangling $\mathrm{OH}$ structures that appear to be either not hydrogen-bonded or more weakly hydrogen-bonded than the average hydrogen-bonded structures in water. ${ }^{34,46-48}$ This band results from water dangling $\mathrm{OH}$ around both solutes. It is not related to a weak intramolecular interaction between the alcohol hydroxy and the $-\mathrm{CF}_{3}$ group in TFE, which has been shown to exist at low temperature and for isolated TFE molecules; ${ }^{88}$ see data and discussion in SI section 1 . Most strikingly, the intensity of the dangling $\mathrm{OH}$ band in the hydration shell of TFE is significantly larger than that in the hydration shell of EtOH. Thus, the hydration shell of TFE not only is less tetrahedral but also contains a larger number of dangling $\mathrm{OH}$ defects than the hydration shell of EtOH.

Figure 2 shows temperature-dependent results obtained in order to further elucidate the thermodynamics associated with

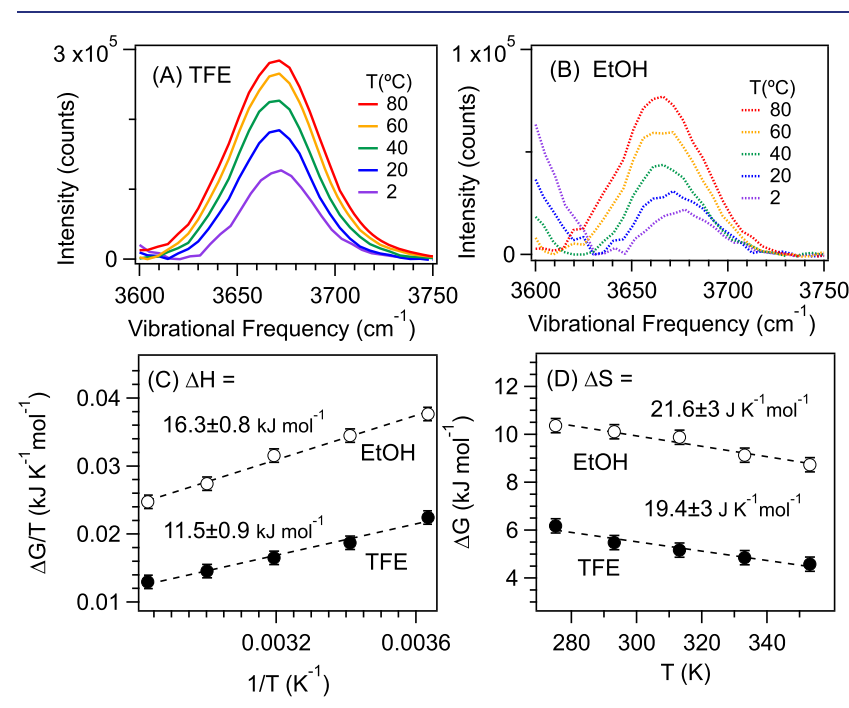

Figure 2. Temperature dependence of the dangling $\mathrm{OH}$ peaks in the hydration shell of (A) TFE and (B) ethanol used to obtain the (C) enthalpy and (D) entropy as associated with the formation of such structures (relative to the structure of pure water). The dangling $\mathrm{OH}$ peaks in panels A and B were obtained from the corresponding SC spectra, after background subtraction in this spectral region. The error bars on the points reflect the experimental reproducibility of the $\mathrm{CH} /$ $\mathrm{OH}$ area ratios, and the error bars on the $\Delta H$ and $\Delta S$ value are obtained from the corresponding error in the slope of the linear fits.

the formation of the dangling $\mathrm{OH}$ defects. Panels $\mathrm{A}$ and $\mathrm{B}$ show the temperature-dependent increase in the intensity of the dangling $\mathrm{OH}$ bands in both the TFE and $\mathrm{EtOH}$ hydration shells. These peaks have been background-subtracted assuming that the background resembled the shape of the $\mathrm{OH}$ stretch band of pure water in this spectral region. Note the different vertical scales in panels $\mathrm{A}$ and $\mathrm{B}$, reflecting the larger intensity of the dangling $\mathrm{OH}$ feature on the hydration shell of TFE than EtOH. Panels $\mathrm{C}$ and D show the temperature dependence of $\Delta G / T=-R \ln \langle k\rangle$ and $\Delta G=-R T \ln \langle k\rangle$ (eq 3), where $\langle k\rangle$ is the average number of dangling $\mathrm{OH}$ structures obtained from the area of the dangling $\mathrm{OH}$ band, after normalization to the solute $\mathrm{CH}$ band area, and correcting for the measured $\mathrm{CH} / \mathrm{OH}$ Raman cross-sectional ratio as further described below. Note 
that $\langle k\rangle$ is expected to be approximately equal to the probability of forming a dangling $\mathrm{OH}$ structure in the hydration shell, and thus, $\Delta G$ is the corresponding Gibbs energy change associated with forming such a structure (relative to pure water), as further described below and consistent with previous work. ${ }^{34}$

The thermodynamics results obtained as described above are shown in Figure 2C,D. These results indicate that, at temperatures ranging from 2 to $80{ }^{\circ} \mathrm{C}$, the $\mathrm{CH} / \mathrm{OH}$ Raman cross-sectional ratios are essentially temperature-independent but are not the same for the two solutes, as the ratio is $1.22 \pm 0.01$ for EtOH and $1.07 \pm 0.02$ for TFE. Our assumption that $f=1$ (in eq 2) implies that the Raman cross section of a dangling $\mathrm{OH}$ group is the same as the average Raman cross section of each $\mathrm{OH}$ group in liquid water. Note that previous theoretical gas-phase water-cluster-based predictions have estimated that the Raman cross section of a dangling $\mathrm{OH}$ group is about half that of a hydrogen-bonded $\mathrm{OH}$ group. ${ }^{34}$ If we had assumed that this cross section ratio also pertains to the dangling $\mathrm{OH}$ defects that we have observed, then that would require setting $f=2$. However, introducing such a Raman cross section change would have a relatively small influence on our spectroscopically derived thermodynamic results, as setting $f$ to 2 rather than 1 would decrease both $\Delta G$ and $-T \Delta S$ by $-R T \ln 2$ (approximately $-1.7 \mathrm{~kJ} / \mathrm{mol}$ at $20{ }^{\circ} \mathrm{C}$ ) and would not have any effect on the experimental $\Delta H$ values. ${ }^{34}$

The results shown in Figure $2 \mathrm{C}$ indicate that the formation of a dangling $\mathrm{OH}$ defect is slightly more favorable (less endothermic) in the hydration shell of TFE than EtOH. This suggests that the dangling $\mathrm{OH}$ is enthalpically stabilized by approximately $-5 \mathrm{~kJ} / \mathrm{mol}$ when interacting with the fluorine atoms on TFE. Such an enthalpic stabilization of dangling $\mathrm{OH}$ like structures has previously been observed to result from the formation of a $\pi$-hydrogen bond between water and benzene, ${ }^{48}$ as well as the formation of a weak hydrogen bond between water and $\mathrm{CO}_{2}{ }^{47}$ The results shown in Figure $2 \mathrm{D}$ indicate that the dangling $\mathrm{OH}$ defects are entropically stabilized to approximately the same extent for both TFE and EtOH (which was also the case in the hydration shells of benzene and $\mathrm{CO}_{2}$ ).

The greater intensity, and thus population, of the water dangling $\mathrm{OH}$ of TFE than of EtOH is consistent with the enthalpic stabilization of the dangling $\mathrm{OH}$ structure by TFE. Given this scenario, the similar frequency of the TFE and EtOH dangling $\mathrm{OH}$ peaks appears at first sight surprising, as several other cases in which the dangling $\mathrm{OH}$-like structures are stabilized have also been accompanied by a red-shift of the dangling $\mathrm{OH}$ peak frequency as might be expected if the dangling $\mathrm{OH}$ is weakly hydrogen bonded. ${ }^{47,48}$ In fact, however, evidence that the relationship between water $\mathrm{OH}$ frequency and hydrogen bond strength is far from straightforward abounds. For example, water-water hydrogen bonds are far more red-shifted than water-benzene $\pi$ hydrogen bonds, although both have similar bond strengths $(\Delta \Delta H$ is only $3 \mathrm{~kJ} /$ $\mathrm{mol}){ }^{48}$ the water-benzene and water-phenol $\pi$ hydrogen bonds differ in strength by $\Delta \Delta H=4 \mathrm{~kJ} / \mathrm{mol}$, but the donating water $\mathrm{OH}$ has the same frequency. ${ }^{48}$ More generally, calculations assuming that frequency shifts are simply Stark shifts show that water hydrogen bond strength correlates remarkably imperfectly with $\mathrm{OH}$ frequency, ${ }^{89}$ and $\mathrm{ab}$ initio calculations $^{90,91}$ have shown that hydrogen bonds involving nonpolar donor $(\mathrm{X}-\mathrm{H})$ groups may be either blue- or red- shifted. Our present work and the literature examples cited here suggest that such nonmonotonic behavior may also occur in the case of polar $\mathrm{O}-\mathrm{H}$ groups, but definitively settling this question will require future detailed theoretical studies. The available evidence supports the notion that the minimal redshift of the TFE dangling $\mathrm{OH}$, and the different temperature dependence of the dangling $\mathrm{OH}$ frequency in both systems, is not inconsistent with the fact that the $-\mathrm{CF}_{3} \cdots \mathrm{HO}-$ interaction is energetically (or enthalpically) more favorable than the $-\mathrm{CH}_{3} \cdots \mathrm{HO}-$ interaction, as clearly evidenced by the temperature dependence of the dangling $\mathrm{OH}$ peak intensities (discussed above).

Simulation Results. Validating Force Fields against Experimental Free Energies of Hydration of EtOH and TFE. The free energies of hydration calculated here correspond to the process of bringing a single solute molecule from the gas phase to the same volume of water, without self-interactions, and do not include the cost of polarizing the molecule when bringing it into water. This cost is expected to be small $(\approx 1$ $\left.\mathrm{kcal} \mathrm{mol}^{-1}\right)^{54}$ and should be similar for $\mathrm{EtOH}$ and TFE because, given the low polarizability of hydrogen and of fluorine, it will arise mostly from the polarization of the alcohol $\mathrm{OH}$.

Free energies of hydration were initially calculated for a subset of force fields (EtOH-GAFF, EtOH-OPLS, TFEVymĕtal , and TFE-Gerig), describing either EtOH or TFE, available in the literature (see Methods). The free energy of hydration of EtOH is better captured with the GAFF than with the OPLS force field (Table 1). The apparently good

Table 1. Free Energy of Hydration ( $\left.\mathrm{kJ} \mathrm{mol}^{-1}\right)$ of Ethanol and Trifluoroethanol at $298 \mathrm{~K}$ from Experiment ${ }^{28}$ and Calculated (FEP) Using the Indicated Force Fields ${ }^{a}$

$\begin{array}{lcc} & \Delta G_{\text {Hyd,FEP }} & \Delta G_{\text {Hyd,Exp }} \\ \text { EtOH-OPLS } & -19.228 \pm 0.013 & -20.962 \\ \text { EtOH-GAFF } & -20.270 \pm 0.021 & \\ \text { EtOH-GAFF } & -22.968 \pm 0.034 & \\ & & \\ \text { TFE-Vymĕtal } & -21.594 \pm 0.047 & -18.033 \\ \text { TFE-Gerig } & -14.758 \pm 0.032 & \\ \text { TFE-Robalo } & -12.984 \pm 0.024 & \\ \text { TFE-Robalo } & -13.963 \pm 0.018 & \end{array}$

${ }^{a}$ Simulation data are presented as the sample mean and standard error of the mean of five independent FEP simulations.

performance of EtOH-GAFF masks the fact that the GAFF force field LJ parameters result in too hydrophobic alkyl moieties: the hydration free energies calculated with GAFF for methane and ethane in TIP4P-Ew water are 10.67 and $10.96 \mathrm{~kJ}$ $\mathrm{mol}^{-1}$ (ref 92), whereas the experimental values are 8.38 and $7.66 \mathrm{~kJ} \mathrm{~mol}^{-1}$, respectively. ${ }^{28}$

In the case of the TFE, the Vymetal force field provides the best agreement with the experimentally measured $\Delta G_{\mathrm{Hyd}}$ though the difference between experiment and simulation is still large $\left(3.6 \mathrm{~kJ} \mathrm{~mol}^{-1}\right.$ absolute difference). For the purpose of comparing the differences in hydration between TFE and $\mathrm{EtOH}$, however, TFE-Vymětal is the worst performing model because it has a more favorable hydration free energy than EtOH-GAFF or EtOH-OPLS, in clear disagreement with experiment. A striking feature of the TFE-Vymëtal force field is the uncommonly large partial charges on the fluorinated group $\left(q_{\mathrm{F}}=-0.32185 e\right.$ and $\left.q_{\mathrm{C}}=+0.90665 e\right)$ when compared to the 
charges obtained from the above-described RESP fit ( $q_{\mathrm{F}}=$ $-0.181277 e$ and $q_{\mathrm{C}}=+0.475746 e$; see Figure S3). The resulting electrostatic interactions with water can (and do, as described in SI section 6) have a drastic impact on the occurrence of dangling hydroxy structures.

Given that the force fields that are best at reproducing the hydration free energy of each molecule have a somewhat incorrect description of the interaction between water and the $-\mathrm{CH}_{3} / \mathrm{CF}_{3}$ groups, we opted to also include other force fields in this study that minimize that shortcoming. The EtOHGAFF $_{\mathrm{H}}$ model is similar to EtOH-GAFF but uses hydrogen LJ parameters optimized against the hydration free energy of ethane (see SI section 2 and Figure S2). The TFE-Robalo model in Table 1 is GAFF-based but uses fluorine LJ parameters optimized against the hydration free energy of $\mathrm{CF}_{4}$. Finally, the TFE-Robalo $\mathrm{H}_{\mathrm{H}}$ model is also GAFF-based but uses the same optimized $\varepsilon_{\mathrm{H}, \mathrm{H}}$ as EtOH-GAFF $\mathrm{H}_{\mathrm{H}}$ and the same optimized fluorine LJ parameters as TFE-Robalo.

Models EtOH-GAFF ${ }_{\mathrm{H}}$, TFE-Robalo, and TFE-Robalo $\mathrm{H}_{\mathrm{H}}$ thus best describe the local interactions between water and the $-\mathrm{CH}_{3} / \mathrm{CF}_{3}$ groups, which are the focus of this work. These local interactions clearly matter for the hydration free energies: $\Delta G_{\mathrm{Hyd}, \mathrm{FEP}}$ is $2.7 \mathrm{~kJ} \mathrm{~mol}^{-1}$ more negative for EtOH-GAFF than for EtOH-GAFF and is $1 \mathrm{~kJ} \mathrm{~mol}^{-1}$ more negative for TFE-Robalo $_{H}$ than for TFE-Robalo. Nevertheless, the negative hydration free energies of $\mathrm{EtOH}$ and TFE arise from the interactions between the alcohol $\mathrm{OH}$ and water. Better agreement with experimental $\Delta G_{\mathrm{Hyd}}$ for TFE could be obtained by optimizing those interactions, but given that this work is not concerned with them, the existing level of agreement (to within $1 \mathrm{kcal} \mathrm{mol}^{-1}$ ) was considered sufficient.

Identifying the Population of Dangling $\mathrm{OH}$ Groups from Simulation. Simulations were performed with multiple force fields for EtOH and TFE. In the main text we focus on the models that best describe the local interaction of water with the hydrophobic part of the solute while still qualitatively reproducing the differences in the hydration free energies of EtOH and TFE. Results for all models are shown and discussed in the Supporting Information and are referenced in the main text as appropriate.

To identify the specific population of $\mathrm{OH}$ groups that yields the high-frequency $\mathrm{OH}$ band detected in Raman-MCR, we tested multiple criteria that select $\mathrm{OH}$ groups that are not (or are only weakly) hydrogen-bonded. The overall most consistent definition (comparing with the thermodynamics of dangling $\mathrm{OH}$ structure formation obtained from Raman-MCR) is to consider dangling $\mathrm{OH}$ groups that do not donate a hydrogen bond to another water molecule and that point to the $-\mathrm{CF}_{3}$ (TFE) or $-\mathrm{CH}_{3}(\mathrm{EtOH})$ group, as illustrated in Figure 3. The simulations also suggest that non-hydrogen-

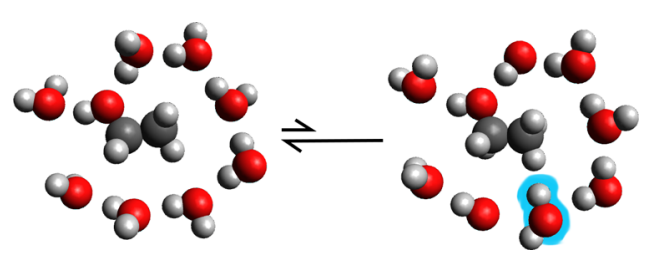

Figure 3. Illustration of the formation of a dangling $\mathrm{OH}$ structure in the hydration shell of ethanol. A hydrophobic hydration shell with no dangling $\mathrm{OH}$ structures is in equilibrium with a hydration shell with exactly one dangling $\mathrm{OH}$ structure (blue halo). bonded hydroxy groups with other orientations contribute to some extent to the dangling $\mathrm{OH}$ band detected in the RamanMCR spectra of TFE (but not of EtOH) as discussed in SI section 4. This contribution is secondary, however. The discussion in the main text is based on the following definition of dangling $\mathrm{OH}$ structures: the water oxygen is within $3.5 \AA$ of a fluorine $\left(-\mathrm{CF}_{3}\right)$ or a hydrogen $\left(-\mathrm{CH}_{3}\right)$ atom, and the $\mathrm{O}-\mathrm{H} \cdots \mathrm{F} / \mathrm{H}$ angle is $160^{\circ}<\theta<180^{\circ}$. This stringent definition yields the best agreement for the thermodynamics of dangling $\mathrm{OH}$ structures between SC Raman-MCR and simulation for both solutions. Our qualitative conclusions hold also for a broader definition (see SI section 6).

Figure 4 shows the number of dangling $\mathrm{OH}$ structures in the hydration shell of $-\mathrm{CF}_{3}$ (TFE) and $-\mathrm{CH}_{3}(\mathrm{EtOH})$ from

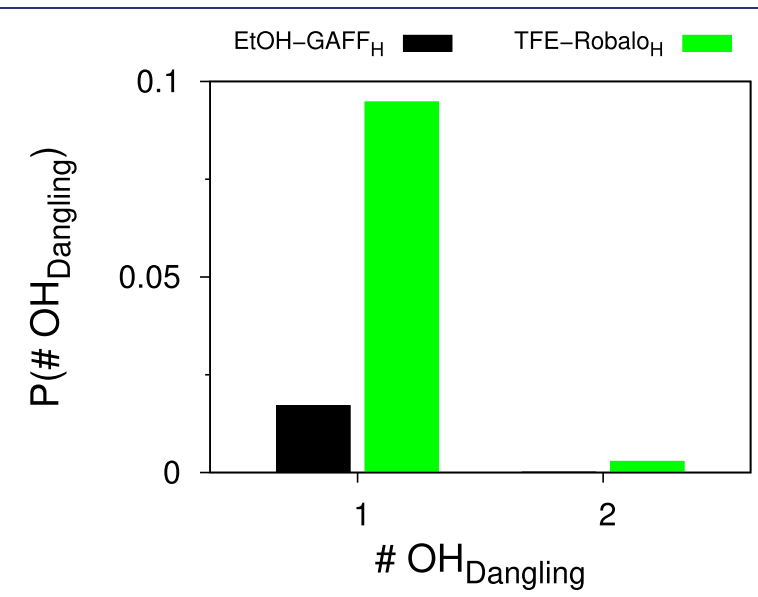

Figure 4. Probability of observing either 1 or 2 dangling water hydroxy structures in the hydration shell of $-\mathrm{CF}_{3}$ (TFE; green) or $-\mathrm{CH}_{3}$ (EtOH; black), calculated with $\mathrm{MD}$ at $298 \mathrm{~K}$ using a stringent definition of dangling hydroxy $\left(P(\geq 3)<5 \times 10^{-5}\right)$.

classical simulations (see Figure S5 for other force fields and criteria to identify defects). Most of the time, the hydration shells of $-\mathrm{CF}_{3}$ and $-\mathrm{CH}_{3}$ have zero dangling $\mathrm{OH}$ structures; the hydration shell of $-\mathrm{CF}_{3}$ contains more dangling $\mathrm{OH}$ structures than that of $-\mathrm{CH}_{3}$; formation of 2 or more simultaneous dangling $\mathrm{OH}$ structures occurs infrequently for both solutes. These trends are consistent with our experimental results, as discussed below.

Thermodynamics of Formation of Dangling Hydroxy Groups Are Similar in Experiment and Simulation. The free energy of formation of dangling hydroxy defects was calculated from MD analogously to what was done experimentally (eq 3) as

$$
\Delta G=-R T \ln \langle k\rangle
$$

where $\langle k\rangle$ is the average number of dangling hydroxys per simulation frame (i.e., per $-\mathrm{CH}_{3}$ or $-\mathrm{CF}_{3}$ hydration shell). For comparison, we also calculated free energies of dangling hydroxy formation as

$$
\Delta G=-R T \ln K
$$

where $K=P_{1} / P_{0}$ and $P_{n}$ is the probability of having a simulation frame with exactly $n$ dangling hydroxys. ${ }^{34} K$ is the equilibrium constant describing the formation of a dangling $\mathrm{OH}$ structure from a hydration shell without defects; $\langle k\rangle$ is a good approximation to $K$ only when defects are rare. The two different definitions of the equilibrium constant yield almost identical free energies, entropies, and enthalpies of dangling 

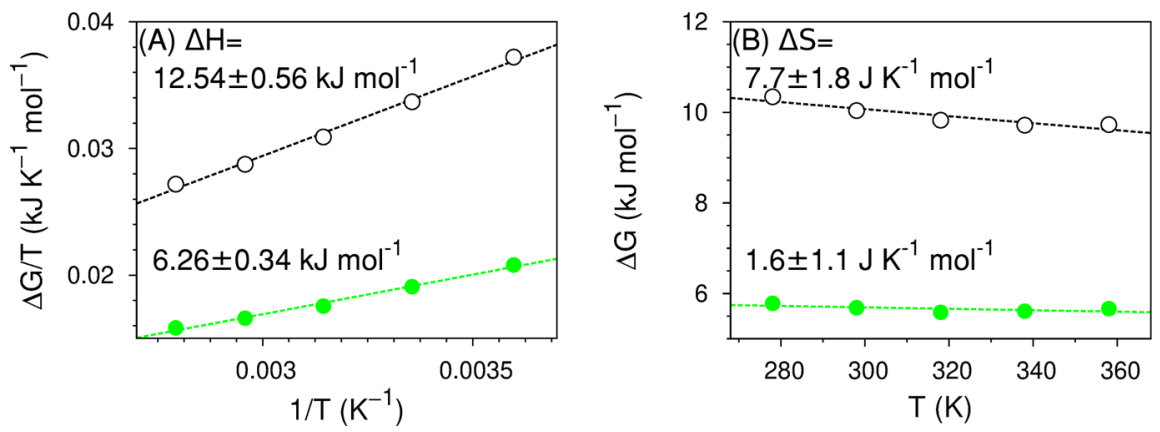

Figure 5. Temperature dependence of the free energy of dangling hydroxy formation for EtOH-GAFF ${ }_{\mathrm{H}}$ (black) or TFE-Robalo ${ }_{\mathrm{H}}$ (green), calculated from MD simulations using a stringent definition of dangling hydroxy. Error bars are of the size of the data points; the data are collected in Table S4. Dashed lines are linear fits to the data. Enthalpies of formation correspond to the slope of the linear fit in panel A, and entropies of formation correspond to the slope of the linear fit in panel B; in both cases, the error corresponds to the error in the slope of the fit.
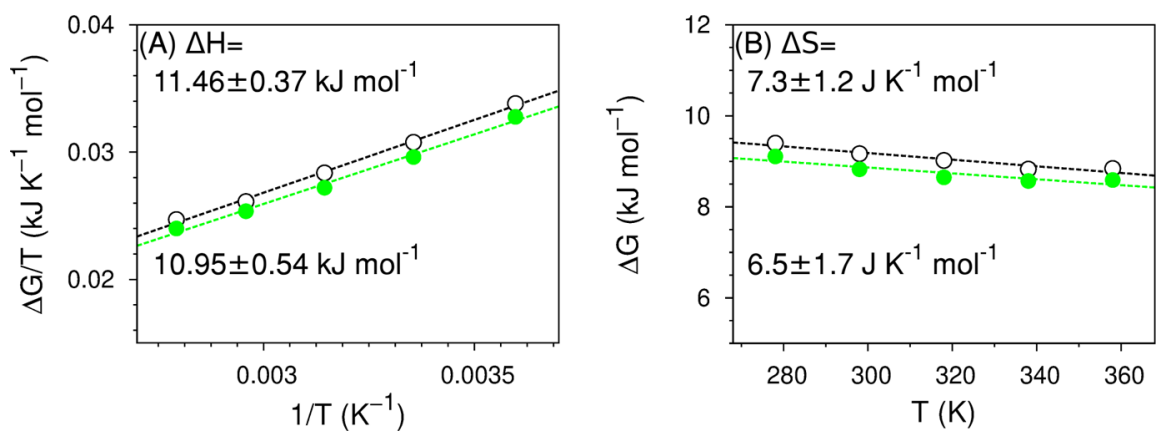

Figure 6. Temperature dependence of the free energy of dangling hydroxy formation for zero-atomic charge EtOH-GAFF $\mathrm{H}_{\mathrm{H}, 0}(\mathrm{black})$ or zero-atomic charge TFE-Robalo $\mathrm{H}_{\mathrm{H}, 0}$ (green), calculated from MD simulations using a stringent definition of dangling hydroxy. Error bars are of the size of the data points; the data are collected in Table S4. Dashed lines are linear fits to the data. Enthalpies of formation correspond to the slope of the linear fit in panel A, and entropies of formation correspond to the slope of the linear fit in panel B; in both cases, the error corresponds to the error in the slope of the fit.

$\mathrm{OH}$ formation for the optimal (stringent) definition of dangling $\mathrm{OH}$ structure (SI section 6, Figures S6 and S7, and Tables S5 and S6), confirming that the approximation $\langle k\rangle=K$ is valid. The discussion that follows is based on thermodynamic quantities obtained from $\langle k\rangle$, to remain close to the Raman-MCR-based analysis.

The free energies of formation of dangling $\mathrm{OH}$ defects obtained with simulation (Figure 5) are similar to those obtained from Raman-MCR (Figure 2(C,D)). $\Delta G$ is positive for both solutes and is larger for EtOH than for TFE, consistent with dangling $\mathrm{OH}$ structures being rarer near EtOH than near TFE. Enthalpies of defect formation from MD are only 4-5 kJ mol${ }^{-1}$ lower (less positive) than the experimental ones. The largest difference between experiment and simulation is seen in the entropies, with entropies calculated from $\mathrm{MD}$ being 1 order of magnitude lower (less positive) than in experiment. Nevertheless, a slightly more positive $\left(\Delta \Delta S=(5 \pm 2) \mathrm{kJ} \mathrm{K}^{-1} \mathrm{~mol}^{-1}\right)$ entropy of defect formation for EtOH than for TFE is observed in simulation, in semiquantitative agreement with experiment $(\Delta \Delta S=$ $\left.(2 \pm 4) \mathrm{kJ} \mathrm{K}^{-1} \mathrm{~mol}^{-1}\right)$. We note that using broad criteria for identifying dangling $\mathrm{OH}$ defects would bring the entropies closer to the experimental values (see SI section 6) at the expense of agreement with the experimental free energies. The stringent definition of dangling $\mathrm{OH}$ structure, used throughout the main text, provides the best overall agreement with experiment, but the same picture emerges using other criteria. More complex molecular models and/or definitions of dangling $\mathrm{OH}$ structures could perhaps bring the simulation results in full agreement with experiment, but our chosen simulation and design setup is clearly sufficient to give insight into formation of the spectroscopically active dangling $\mathrm{OH}$ structures. Changes in the Lennard-Jones parameters of hydrogen have almost negligible impact in the formation of dangling $\mathrm{OH}$ defects: the free energy of formation of defects and the corresponding enthalpies and entropies are almost indistinguishable between EtOH-GAFF $\mathrm{H}_{\mathrm{H}}$ and EtOH-GAFF, and between TFE-Robalo $\mathrm{o}_{\mathrm{H}}$ and TFE-Robalo (Figure S7A and Table S6). In contrast, the results from TFE-Vymětal suggest that the partial charges in the $-\mathrm{CF}_{3}$ group significantly impact the thermodynamics of formation of dangling $\mathrm{OH}$ structures (Figure S7A and Table S6).

The semiquantitative agreement between experiment and simulation with respect to the thermodynamics of formation of dangling $\mathrm{OH}$ defects confirms that this population consists predominantly of water hydroxy groups that belong to the first hydration shell of the $-\mathrm{CH}_{3} / \mathrm{CF}_{3}$ groups and for which the $\mathrm{O}-\mathrm{H}$ vector points to these groups.

Electrostatic Interactions Are Primarily Responsible for Promoting Dangling $\mathrm{OH}$ Defects near TFE. Both simulation and experiment confirm that the formation of dangling $\mathrm{OH}$ in the hydrophobic hydration shells of EtOH and TFE is strongly unfavorable because of the unfavorable enthalpy of the process. This enthalpy is not very sensitive to dispersive interactions between the solute and the water: the nonpolar hydrogen in

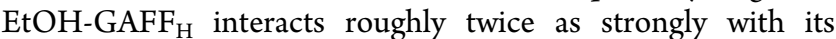
environment as the same hydrogen in EtOH-GAFF (Table S1), but the enthalpy of defect formation is the same (to 

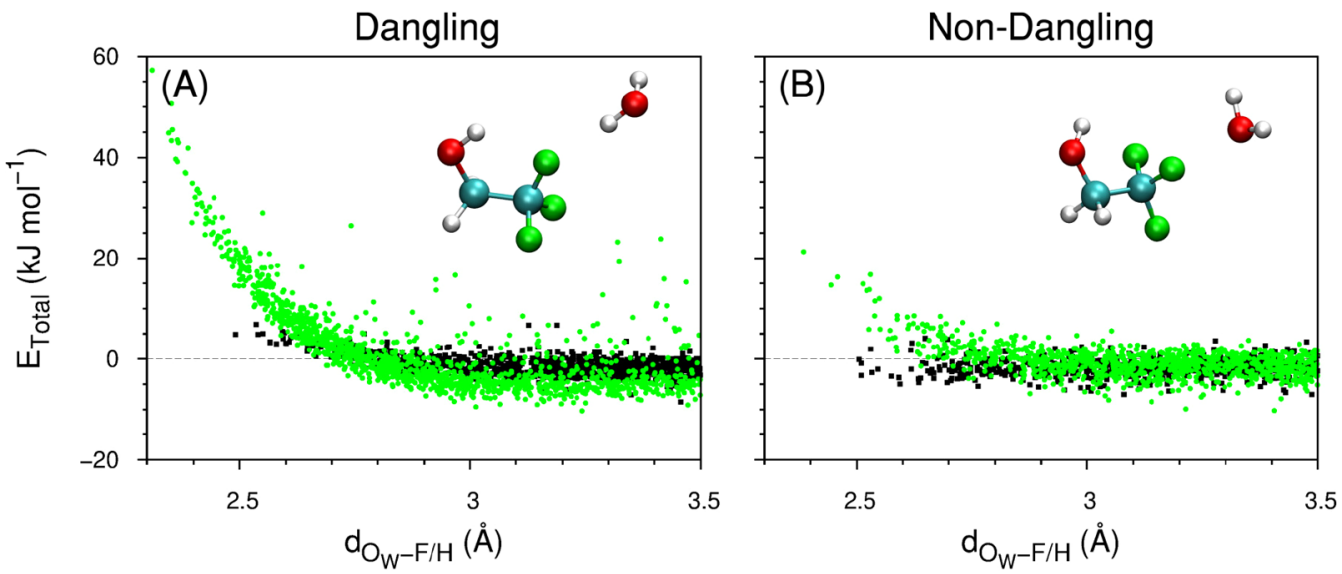

Figure 7. Total interaction energy of a water-alcohol dimer (EtOH-water in black, TFE-water in green) vs the distance between the water oxygen atom and the closest $-\mathrm{CH}_{3}$ hydrogen $(\mathrm{EtOH})$ or $-\mathrm{CF}_{3}$ fluorine (TFE) atom. The water molecule in the dimer has either one or zero dangling hydroxys (left/right-hand side panels, respectively; insets show examples of configurations of water-TFE dimers). Configurations are extracted from MD simulations at $298 \mathrm{~K}$ using the EtOH-GAFF ${ }_{\mathrm{H}}$ and TFE-Robalo $\mathrm{H}_{\mathrm{H}}$ force fields. The number of data points for each configuration is EtOH, dangling: 938; TFE, dangling: 1314; EtOH, nondangling: 689; TFE, nondangling: 1000. Energies are calculated at the DF$\mathrm{SAPT} 2+(\mathrm{CCD}) \delta \mathrm{MP} 2 /$ aug-cc-pVTZ level of theory.

within statistical uncertainty) for both those models (Tables S5 and S6).

To establish the role of electrostatics in the mechanism of formation of dangling $\mathrm{OH}$ defects, we conducted additional NVT simulations of both alcohols, starting from the same configuration as the previous NVT runs, but with null partial charge at each solute atom. The results for these zero-charge solutes are presented in Figure 6 (also Table S7 and Figure S8). It is clear that removing the partial charges on the solute eliminates the difference in the thermodynamics of defect formation between both solutes: $\Delta G$ is now only $0.2 \mathrm{~kJ} \mathrm{~mol}^{-1}$ less positive for TFE than for $\mathrm{EtOH}$ (Figure 6), whereas for the solutes with atomic charges the difference is several kilojoules per mole (Figure 5). These results indicate that, when considering only their Lennard-Jones interactions with water, $-\mathrm{CF}_{3}$ strains the surrounding water network (i.e., facilitates the formation of dangling $\mathrm{OH}$ structures) only marginally more than $-\mathrm{CH}_{3}$ despite its larger volume.

The different Lennard-Jones potential associated with carbon-bound hydrogen and with fluorine implies that methyl and trifluoromethyl groups differ both in size and in the magnitude of their attractive interaction energy with water. To check whether the similarity in the thermodynamics of dangling $\mathrm{OH}$ structure formation observed in Figure 6 for the two zero-charge solutes actually reflects the compensation of these two factors rather than a true independence of volume, we performed an additional control simulation for TFE. In this second control, $-\mathrm{CF}_{3}$ approximately retains its original size, but its attractive interaction with water is now close to that of $-\mathrm{CH}_{3}$; all partial atomic charges are zero. Further details and the corresponding results are presented in SI section 7. Again we find that the thermodynamics of dangling $\mathrm{OH}$ formation in the hydration shell of $-\mathrm{CF}_{3}$ in this TFE is very close to that of $-\mathrm{CH}_{3}$ in the zero charge $\mathrm{EtOH}$, despite their volume difference. These results confirm that the thermodynamics of formation of dangling $\mathrm{OH}$ structures are indeed insensitive to volume changes associated with transforming a $-\mathrm{CH}_{3}$ group into a $-\mathrm{CF}_{3}$ group. It follows that the most informative way to compare the thermodynamics of dangling $\mathrm{OH}$ structures in the hydration shell of these two solutes is to use thermodynamic parameters reported per group as we do, rather than normalized by volume or by area.

Eliminating the partial charges in the solutes has a substantial impact in the formation of dangling $\mathrm{OH}$ defects only around TFE: $\Delta G$ differs substantially between zeroatomic charge TFE-Robalo $\mathrm{H}_{\mathrm{H}, 0}$ and its charged counterpart, whereas it is almost identical between zero-atomic charge EtOH-GAFF $\mathrm{H}_{\mathrm{H}, 0}$ and its charged version (compare Figures 5 and 6. Moreover, changes in $\Delta G$ for TFE when eliminating charges reflect primarily changes in enthalpy: $\Delta H=(10.95 \pm$ $0.5) \mathrm{kJ} \mathrm{mol}^{-1}$ for the zero-atomic charge TFE-Robalo ${ }_{\mathrm{H}, 0}$, whereas $\Delta H=(6.26 \pm 0.3) \mathrm{kJ} \mathrm{mol}^{-1}$ for its charged version. In contrast, $\Delta H=(11.46 \pm 0.4) \mathrm{kJ} \mathrm{mol}^{-1}$ for the zero-atomic charge EtOH-GAFF ${ }_{\mathrm{H}, 0}$ and $(12.54 \pm 0.6) \mathrm{kJ} \mathrm{mol}^{-1}$ for its charged version. It is the high polarity of the $\mathrm{C}-\mathrm{F}$ bond relative to the $\mathrm{C}-\mathrm{H}$ bond that makes the enthalpy of dangling $\mathrm{OH}$ formation in the hydrophobic shell of TFE less positive (less unfavorable) than in EtOH. The picture that emerges is that the thermodynamics of formation of dangling $\mathrm{OH}$ defects is dominated by the enthalpic cost of breaking a water-water hydrogen bond, but around TFE some of that cost is offset by favorable electrostatic interactions between the dangling water hydroxy and fluorine.

For both solutes, breaking a strong water-water hydrogen bond to form a dangling hydroxy is entropically favored because dangling hydroxys can access more configurations. The entropy of defect formation is, however, somewhat less favorable (less positive) for TFE than for EtOH (Figures 2 and 5). Comparison of the entropy of formation of dangling $\mathrm{OH}$ structures of TFE-Robalo ${ }_{\mathrm{H}}\left(\Delta S=(1.6 \pm 1) \mathrm{J} \mathrm{K}^{-1} \mathrm{~mol}^{-1}\right)$ with that of its zero-atomic charge analogue $\left((6.5 \pm 2) \mathrm{J} \mathrm{K}^{-1} \mathrm{~mol}^{-1}\right)$ points to the origin of this difference: the interactions between dangling hydroxys and $-\mathrm{CF}_{3}$ groups are more directional (explore fewer configurations) than with $-\mathrm{CH}_{3}$ groups, again because of the polarity of the $\mathrm{C}-\mathrm{F}$ bond.

Our conclusion that electrostatic interactions are primarily responsible for promoting dangling $\mathrm{OH}$ structures in the hydration shell of $-\mathrm{CF}_{3}$ (relative to $-\mathrm{CH}_{3}$ ) is based on force fields with a commonly used but simple functional form: each atom has a fixed partial charge; dispersion interactions are represented via Lennard-Jones potentials. To put this 
conclusion on firmer ground, we performed symmetry-adapted perturbation theory calculations on water-alcohol dimers and decomposed their interaction energies into induction, electrostatic, exchange, and dispersion contributions. The dimers were obtained from the MD simulations and thus are representative of solution structures (which differ from typical configurations in the gas phase ${ }^{93}$ ). This combination of extensive conformational sampling and subsequent dissection of the pairwise interactions by high-level ab initio methods has, to the best of our knowledge, not yet been employed to investigate the effects of halogenation on solvation. Such approaches have been successful in providing insight into the microscopic behavior of liquid water. ${ }^{94}$

We considered two types of configurations, "dangling" and "nondangling", illustrated in Figure 7. In the dangling configuration the water molecule has 1 hydroxy pointing to $-\mathrm{CF}_{3} /-\mathrm{CH}_{3}$; in the nondangling configuration, neither hydroxy points to those groups. In the MD simulations, the nondangling hydroxys are typically hydrogen-bonded to other water molecules (not included in the SAPT calculations).

Figure 7 shows the total interaction energy for the dimers in the two types of configurations as a function of the distance between the water oxygen and either hydrogen (in $-\mathrm{CH}_{3}$ ) or fluorine (in $-\mathrm{CF}_{3}$ ). Below a threshold of $\sim 2.6 \AA$ for $\mathrm{EtOH}$ and $\sim 2.8 \AA$ for TFE, interatomic repulsion dominates for both dangling and nondangling configurations. Configurations below $2.5 \AA$ do not appear for EtOH because they do not occur in the solution simulations. However, configurations below $2.5 \AA$ are still present in the solution simulations of TFE even though the SAPT calculations for the dimer indicate they are strongly energetically unfavorable. This difference reflects the different way in which TFE and EtOH perturb the collective water network. For nondangling configurations, individual water molecules have negligible interactions with either $\mathrm{EtOH}$ or TFE (Figure 7B): beyond the repulsion threshold, the interaction energy oscillates around 0 . In contrast, waters in dangling conformations are, beyond the same threshold, clearly attracted to TFE-the interaction energy is $\sim-5 \mathrm{~kJ} \mathrm{~mol}^{-1}-$ but continue to interact negligibly with $\mathrm{EtOH}$ (Figure 7A). These results are consistent with the lower (less positive) enthalpy of formation of dangling $\mathrm{OH}$ defects near $-\mathrm{CF}_{3}$ relative to $-\mathrm{CH}_{3}$ observed both in $\mathrm{MD}$ and Raman-MCR: this enthalpy is positive because of breaking a water-water hydrogen bond, but part of this cost is offset for TFE because of attractive interactions between TFE and the water with the dangling $\mathrm{OH}$ defect.

To understand the origin of the favorable enthalpic interaction between dangling $\mathrm{OH}$ structures and TFE, we calculated the various components of the interaction energy of the dimers as a function of distance (see Figure S9). In Figure 8 we show the difference, $\Delta\langle E\rangle_{\mathrm{F}-\mathrm{H}}$, of the average contribution of each interaction energy component, where the average is done for distances beyond the repulsive thresholds. For the nondangling configurations, all components have low absolute magnitude and $\Delta\langle E\rangle_{\mathrm{F}-\mathrm{H}}$ is close to zero for all of them.

The situation changes for the dangling configurations: dispersion (attractive) interactions are now substantially more intense for the TFE-water dimer than for EtOH-water, but likewise for the repulsive exchange component. The largest difference between TFE-water and EtOH-water dimers in dangling configurations is seen for the (attractive) electrostatic interaction: it is negligible for $\mathrm{EtOH}-$

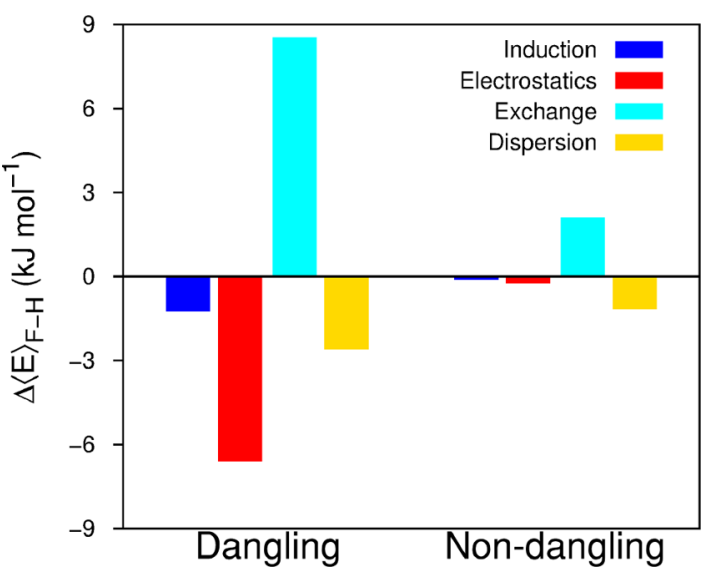

Figure 8. Difference of the average contributions $\left(\Delta\langle E\rangle_{\mathrm{F}-\mathrm{H}}=\langle E\rangle_{\mathrm{TFE}}\right.$ $\left.-\langle E\rangle_{\mathrm{EtOH}}\right)$ of induction, electrostatics, exchange, and dispersion to the total interaction energy of a water-EtOH/TFE dimer. The water molecule in the dimer has either one or zero dangling hydroxy structures. Averages are calculated over all configurations for which the energy is beyond the repulsive threshold (2.6 $\AA$ for $\mathrm{EtOH}, 2.8 \AA$ for TFE; see Figures 7 and S9).

water but markedly attractive for TFE-water, in line with our force field-based observations.

\section{CONCLUDING REMARKS}

The emerging picture is that $-\mathrm{CF}_{3}$ indeed has the typical, weak enthalpic interactions with water molecules expected of hydrophobic moieties immersed in water (Figure 7B) but is nevertheless not a typical hydrophobe. Dangling $\mathrm{OH}$ defects are substantially less rare in the hydration shell of $-\mathrm{CF}_{3}$ than of $-\mathrm{CH}_{3}$ (Figures 2 and 5) because the $\mathrm{O}-\mathrm{H}$ bond vector pointing toward the solute is weakly stabilized by the polar CF bond (Figures 6 and 8). This interaction somewhat offsets the enthalpic cost of breaking strong water-water hydrogen bonds.

Interactions between hydroxys and the $\mathrm{C}-\mathrm{F}$ bond in perfluoroalkyl groups have been detected using rotational spectroscopy in clusters of fluorinated alcohols in the gas phase; ${ }^{95}$ they have also been detected in clusters of water with TFE in supersonic jet FTIR experiments. ${ }^{93}$ The present work is the first quantitative, experimentally based confirmation that these interactions, although weak compared with water-water interactions, matter even in the presence of excess water.

Our prior simulation work indicates that dangling water hydroxys also exist in the hydration shell of $-\mathrm{CF}_{3}$ in the side chain of noncanonical amino acids and that the $-\mathrm{CF}_{3} \cdots \mathrm{HOH}$ interaction is a non-negligible contribution to the free energy of hydration of tri- and hexafluorinated amino acids. ${ }^{92}$ The magnitude of the contribution of $-\mathrm{CF}_{3} \cdots \mathrm{HOH}$ interactions for the $\Delta G_{\mathrm{Hyd}}$ of amino acids ${ }^{92}$ and the present results suggest that dangling $\mathrm{OH}$ defects in the hydration shell of $-\mathrm{CF}_{3}$ are weak hydrogen bonds, despite the almost negligible red-shift in the $\mathrm{OH}$ stretch frequency (Figure 2).

Our results hint that $-\mathrm{CF}_{3}$ will deviate substantially from the typical $\left(-\mathrm{CH}_{3}\right)$ hydrophobe particularly under low hydration conditions, e.g., under confinement in protein-binding pockets or in crevices on the protein surface. Under these conditions, water-water hydrogen bonds are often fewer or more distorted than in the bulk. ${ }^{96}$ The resulting dangling $\mathrm{OH}$ defects may be stabilized by interactions with nearby $-\mathrm{CF}_{3}$ (but not with $-\mathrm{CH}_{3}$ ). As a result, the thermodynamics of 
protein folding and protein-protein or protein-ligand binding may be affected by the substitution of $-\mathrm{CH}_{3}$ by $-\mathrm{CF}_{3}$ much beyond what would be expected for the associated volume change. Inhibition studies of the BPTI- $\beta$-trypsin system suggest this scenario is possible. ${ }^{14}$ Replacing $-\mathrm{CH}_{3}$ by $-\mathrm{CF}_{3}$ in the side chain of the aminobutanoic amino acid in position 15 of a mutant-BPTI dramatically increases binding to (inhibition of) $\beta$-trypsin. X-ray crystallography shows that the binding pocket in both systems contains water molecules in similar positions, but with different dynamics as measured by the $B$-factor. Systems such as the mouse major urinary protein, the oligopeptide binding protein, the bovine apo-glycolipid transfer protein, or the secretin pilot protein, whose binding sites accommodate water, are interesting possibilities to further investigate the generality of this mechanism.

Fluorinated solvents often beneficially impact the kinetics, regioselectivity, and stereoselectivity of reactions for reasons that are not completely understood. ${ }^{97}$ The possibility that these changes occur via the facilitated interaction of dangling water $\mathrm{OH}$ groups with transition states, similarly to what has been proposed for "on water" reactions in the presence of nonfluorinated hydrophobes, ${ }^{98}$ is worth exploring.

Prior work has shown that the hydration and aggregation of hydrophobes depend strongly on the details of the solute (or of the substituents in the solute), including the volume, curvature, and magnitude of attractive solute-water interactions. $^{13,15,22,34,35,86,99-117}$ Our work adds to this body and provides the strongest evidence to date that perfluoroalkyl groups are a different category of hydrophobe. Our results prove that, contrary to expectations, the larger volume of $-\mathrm{CF}_{3}$ is not the reason why this solute has a larger number of dangling $\mathrm{OH}$ structures in its hydration shell, in contrast to expectations based on classical theories of hydrophobicity $^{118,119}$ Other observables characterizing hydration may well reflect the volume difference between perfluoroalkanes/alkyl groups and their nonfluorinated analogues, but this dependence should be proven rather than assumed. Our approach (using control simulations with zero-charge solutes) is a useful pathway to understand the thermodynamics of hydration or of aggregation of molecules with perfluorolkyl groups, which cannot be fully understood in terms of their larger volume (relative to the corresponding alkylated moieties) as discussed above. ${ }^{1,13,25-28,30}$

\section{ASSOCIATED CONTENT}

\section{S Supporting Information}

The Supporting Information is available free of charge on the ACS Publications website at DOI: 10.1021/jacs.9b06862.

Spectra of pure EtOH, TFE, and TFE in EtOH; optimization of the Lennard-Jones parameters of nonpolar hydrogens against the free energy of hydration of ethane; partial atomic charges of $\mathrm{EtOH}$ and TFE; free energy, enthalpy, and entropy of formation of dangling $\mathrm{OH}$ structures for different criteria used to identify them in the simulations and for all force fields; tables with the data for all plots in the main text; energy component versus distance calculated using SAPT for alcohol-water dimers (PDF)

\section{AUTHOR INFORMATION}

\section{Corresponding Author}

*ana.vilaverde@mpikg.mpg.de
ORCID

Denilson Mendes de Oliveira: 0000-0002-2579-8405

Petra Imhof: 0000-0001-9820-4578

Dor Ben-Amotz: 0000-0003-4683-5401

Ana Vila Verde: 0000-0003-0337-3972

\section{Present Address}

"P.I.: University of Stavanger, Department of Chemistry, Bioscience and Environmental Engineering, Postfach 8600 Forus, 4036 Stavanger, Norway.

\section{Notes}

The authors declare no competing financial interest.

\section{ACKNOWLEDGMENTS}

We thank Milana Zaric for help setting up SAPT calculations. Support for D.B.-A., L.M.S., and D.M.O. was provided by the U.S. National Science Foundation (CHE-1763581) and Purdue University. J.R.R., P.I., and A.V.V. acknowledge support by the Deutsche Forschungsgemeinschaft (SPP 1807). Computational resources provided by the NorthGerman Supercomputing Alliance (HLRN) are gratefully acknowledged.

\section{REFERENCES}

(1) Wilhelm, E.; Battino, R.; Wilcock, R. J. Low-pressure solubility of gases in liquid water. Chem. Rev. 1977, 77, 219-262.

(2) Tretinnikov, O. N.; Ikada, Y. Dynamic wetting and contact-angle hysteresis of polymer surfaces studies with the modified Wilhelmy balance method. Langmuir 1994, 10, 1606-1614.

(3) Salwiczek, M.; Nyakatura, E. K.; Gerling, U. I. M.; Ye, S.; Koksch, B. Fluorinated amino acids: Compatibility with native protein structures and effects on protein-protein interactions. Chem. Soc. Rev. 2012, 41, 2135-2171.

(4) Biava, H.; Budisa, N. Evolution of fluorinated enzymes: An emerging trend for biocatalyst stabilization. Eng. Life Sci. 2014, 14, 340-351.

(5) Bilgiçer, B.; Xing, X.; Kumar, K. Programmed self-sorting of coiled coils with leucine and hexafluoroleucine cores. J. Am. Chem. Soc. 2001, 123, 11815-11816.

(6) Buer, B. C.; Levin, B. J.; Marsh, E. N. G. Influence of fluorination on the thermodynamics of protein folding. J. Am. Chem. Soc. 2012, 134, 13027-13034.

(7) Buer, B. C.; Meagher, J. L.; Stuckey, J. A.; Marsh, E. N. G. Structural basis for the enhanced stability of highly fluorinated proteins. Proc. Natl. Acad. Sci. U. S. A. 2012, 109, 4810-4815.

(8) Clark, G. A.; Baleja, J. D.; Kumar, K. Cross-strand interactions of fluorinated amino acids in $\beta$-hairpin constructs. J. Am. Chem. Soc. 2012, 134, 17912-17921.

(9) Huhmann, S.; Nyakatura, E. K.; Erdbrink, H.; Gerling, U. I.; Czekelius, C.; Koksch, B. Effects of single substitutions with hexafluoroleucine and trifluorovaline on the hydrophobic core formation of a heterodimeric coiled coil. J. Fluorine Chem. 2015, $175,32-35$.

(10) Asante, V.; Mortier, J.; Schlüter, H.; Koksch, B. Impact of fluorination on proteolytic stability of peptides in human blood plasma. Bioorg. Med. Chem. 2013, 21, 3542-3546.

(11) Asante, V.; Mortier, J.; Wolber, G.; Koksch, B. Impact of fluorination on proteolytic stability of peptides: A case study with $\alpha$ chymotrypsin and pepsin. Amino Acids 2014, 46, 2733-2744.

(12) Berger, A. A.; Völler, J. S.; Budisa, N.; Koksch, B. Deciphering the fluorine code-The many hats fluorine wears in a protein environment. Acc. Chem. Res. 2017, 50, 2093-2103.

(13) Mecinović, J.; Snyder, P. W.; Mirica, K. A.; Bai, S.; Mack, E. T.; Kwant, R. L.; Moustakas, D. T.; Héroux, A.; Whitesides, G. M. Fluoroalkyl and alkyl chains have similar hydrophobicities in binding to the "hydrophobic wall" of carbonic anhydrase. J. Am. Chem. Soc. 2011, 133, 14017-14026. 
(14) Ye, S.; Loll, B.; Berger, A. A.; Mülow, U.; Alings, C.; Wahl, M. C.; Koksch, B. Fluorine teams up with water to restore inhibitor activity to mutant BPTI. Chem. Sci. 2015, 6, 5246-5254.

(15) Lee, A.; Mirica, K. A.; Whitesides, G. M. Influence of fluorocarbon and hydrocarbon acyl groups at the surface of bovine carbonic anhydrase II on the kinetics of denaturation by sodium dodecyl sulfate. J. Phys. Chem. B 2011, 115, 1199-1210.

(16) Polidori, A.; Raynal, S.; Barret, L.-A.; Dahani, M.; Barrot-Ivolot, C.; Jungas, C.; Frotscher, E.; Keller, S.; Ebel, C.; Breyton, C.; Bonneté, F. Sparingly fluorinated maltoside-based surfactants for membrane-protein stabilization. New J. Chem. 2016, 40, 5364-5378.

(17) Oliver, M.; Gadais, C.; García-Pindado, J.; Teixidó, M.; Lensen, N.; Chaume, G.; Brigaud, T. Trifluoromethylated proline analogues as efficient tools to enhance the hydrophobicity and to promote passive diffusion transport of the L-prolyl-L-leucyl glycinamide (PLG) tripeptide. RSC Adv. 2018, 8, 14597-14602.

(18) Purser, S.; Moore, P. R.; Swallow, S.; Gouverneur, V. Fluorine in medicinal chemistry. Chem. Soc. Rev. 2008, 37, 320-330.

(19) Prchalová, E.; Stěpánek, O.; Smrček, S.; Kotora, M. Medicinal applications of perfluoroalkylated chain-containing compounds. Future Med. Chem. 2014, 6, 1201-1229.

(20) Fujiwara, T.; O’Hagan, D. Successful fluorine-containing herbicide agrochemicals. J. Fluorine Chem. 2014, 167, 16-29.

(21) Haranahalli, K.; Honda, T.; Ojima, I. Recent progress in the strategic incorporation of fluorine into medicinally active compounds. J. Fluorine Chem. 2019, 217, 29-40.

(22) Ben-Amotz, D. Water-mediated hydrophobic interactions. Annu. Rev. Phys. Chem. 2016, 67, 617-638.

(23) Mondal, S.; Biswas, B.; Nandy, T.; Singh, P. C. Understanding the role of hydrophobic terminal in the hydrogen bond network of the aqueous mixture of 2,2,2-trifluoroethanol: IR, molecular dynamics, quantum chemical as well as atoms in molecules studies. J. Phys. Chem. B 2018, 122, 6616-6626.

(24) Bergstrom, P. A.; Lindgren, J. On the hydration of the trifluoroacetate ion $\left(\mathrm{CF}_{3} \mathrm{COO}^{-}\right)$in aqueous solution. J. Mol. Struct. 1991, 245, 221-229.

(25) Wen, W.-Y.; Muccitelli, J. A. Thermodynamics of some perfluorocarbon gases in water. J. Solution Chem. 1979, 8, 225-246.

(26) Rettich, T. R.; Handa, Y. P.; Battino, R.; Wilhelm, E. Solubility of gases in liquids. 13. High-precision determination of Henry's constants for methane and ethane in liquid water at 275 to $328 \mathrm{~K}$. J. Phys. Chem. 1981, 85, 3230-3237.

(27) Bonifácio, R. P.; Pádua, A. A. H.; Costa Gomes, M. F. Perfluoroalkanes in water: Experimental Henry's law coefficients for hexafluoroethane and computer simulations for tetrafluoromethane and hexafluoroethane. J. Phys. Chem. B 2001, 105, 8403-8409.

(28) Marenich, A. V.; Kelly, C. P.; Thompson, J. D.; Hawkins, G. D.; Chambers, C. C.; Giesen, D. J.; Winget, P.; Cramer, C. J.; Truhlar, D. G. Minnesota Solvation Database, version 2012; 2012.

(29) Dalvi, V. H.; Rossky, P. J. Molecular origins of fluorocarbon hydrophobicity. Proc. Natl. Acad. Sci. U. S. A. 2010, 107, 1360313607.

(30) Adam, C.; Yang, L. X.; Cockroft, S. L. Partitioning solvophobic and dispersion forces in alkyl and perfluoroalkyl cohesion. Angew. Chem., Int. Ed. 2015, 54, 1164-1167.

(31) Du, Q.; Superfine, R.; Freysz, E.; Shen, Y. R. Vibrational spectroscopy of water at the vapor/water interface. Phys. Rev. Lett. 1993, 70, 2313-2316.

(32) Du, Q.; Freysz, E.; Shen, Y. Surface vibrational spectroscopic studies of hydrogen-bonding and hydrophobicity. Science 1994, 264, $826-828$.

(33) Tomlinson-Phillips, J.; Davis, J.; Ben-Amotz, D.; Spångberg, D.; Pejov, L.; Hermansson, K. Structure and dynamics of water dangling $\mathrm{OH}$ bonds in hydrophobic hydration shells. Comparison of simulation and experiment. J. Phys. Chem. A 2011, 115, 6177-6183.

(34) Davis, J. G.; Rankin, B. M.; Gierszal, K. P.; Ben-Amotz, D. On the cooperative formation of non-hydrogen-bonded water at molecular hydrophobic interfaces. Nat. Chem. 2013, 5, 796-802.
(35) Ben-Amotz, D. Hydrophobic ambivalence: Teetering on the edge of randomness. J. Phys. Chem. Lett. 2015, 6, 1696-1701.

(36) Hsieh, C.-S.; Campen, R. K.; Vila Verde, A. C.; Bolhuis, P.; Nienhuys, H.-K.; Bonn, M. Ultrafast reorientation of dangling $\mathrm{OH}$ groups at the air/water interface. Phys. Rev. Lett. 2011, 107, 116102.

(37) Tong, Y.; Vila Verde, A.; Campen, R. K. The free OD at the air $/ \mathrm{D}_{2} \mathrm{O}$ interface is structurally and dynamically heterogeneous. $J$. Phys. Chem. B 2013, 117, 11753-11764.

(38) Stiopkin, I. V.; Weeraman, C.; Pieniazek, P. A.; Shalhout, F. Y.; Skinner, J. L.; Benderskii, A. V. Hydrogen bonding at the water surface revealed by isotopic dilution spectroscopy. Nature 2011, 474, 192-195.

(39) Jedlovszky, P. The hydrogen bonding structure of water in the vicinity of apolar interfaces: a computer simulation. J. Phys.: Condens. Matter 2004, 16, S5389-S5402.

(40) Stirnemann, G.; Rossky, P. J.; Hynes, J. T.; Laage, D. Water reorientation, hydrogen-bond dynamics and 2D-IR spectroscopy next to an extended hydrophobic surface. Faraday Discuss. 2010, 146, 263-281.

(41) Kühne, T. D.; Pascal, T. A.; Kaxiras, E.; Jung, Y. New insights into the structure of the vapor/water interface from large-scale firstprinciples simulations. J. Phys. Chem. Lett. 2011, 2, 105-113.

(42) Vila Verde, A.; Bolhuis, P. G.; Campen, R. K. Statics and dynamics of free and hydrogen-bonded $\mathrm{OH}$ groups at the air/water interface. J. Phys. Chem. B 2012, 116, 9467-9481.

(43) Kessler, J.; Elgabarty, H.; Spura, T.; Karhan, K.; Partovi-Azar, P.; Hassanali, A. A.; Kühne, T. D. Structure and dynamics of the instantaneous water/vapor interface revisited by path-integral and $a b$ initio molecular dynamics simulations. J. Phys. Chem. B 2015, 119, 10079-10086.

(44) Strazdaite, S.; Versluis, J.; Bakker, H. J. Water orientation at hydrophobic interfaces. J. Chem. Phys. 2015, 143, No. 084708.

(45) Tang, F.; Ohto, T.; Hasegawa, T.; Xie, W. J.; Xu, L.; Bonn, M.; Nagata, Y. Definition of free O-H groups of water at the air-water interface. J. Chem. Theory Comput. 2018, 14, 357-364.

(46) Perera, P. N.; Fega, K. R.; Lawrence, C.; Sundstrom, E. J.; Tomlinson-Phillips, J.; Ben-Amotz, D. Observation of water dangling $\mathrm{OH}$ bonds around dissolved nonpolar groups. Proc. Natl. Acad. Sci. U. S. A. 2009, 106, 12230-12234.

(47) Zukowski, S. R.; Mitev, P. D.; Hermansson, K.; Ben-Amotz, D. $\mathrm{CO}_{2}$ hydration shell structure and transformation. J. Phys. Chem. Lett. 2017, 8, 2971-2975.

(48) Gierszal, K. P.; Davis, J. G.; Hands, M. D.; Wilcox, D. S.; Slipchenko, L. V.; Ben-Amotz, D. $\pi$-Hydrogen bonding in liquid water. J. Phys. Chem. Lett. 2011, 2, 2930-2933.

(49) Davis, J. G.; Gierszal, K. P.; Wang, P.; Ben-Amotz, D. Water structural transformation at molecular hydrophobic interfaces. Nature 2012, 491, 582-585.

(50) Lawton, W. H.; Sylvestre, E. A. Self-modeling curve resolution. Technometrics 1971, 13, 617-633.

(51) Horn, H. W.; Swope, W. C.; Pitera, J. W.; Madura, J. D.; Dick, T. J.; Hura, G. L.; Head-Gordon, T. Development of an improved four-site water model for biomolecular simulations: TIP4P-Ew. J. Chem. Phys. 2004, 120, 9665-9678.

(52) Jorgensen, W. L.; Maxwell, D. S.; Tirado-Rives, J. Development and testing of the OPLS all-atom force field on conformational energetics and properties of organic liquids. J. Am. Chem. Soc. 1996, $118,11225-11236$.

(53) Wang, J.; Wolf, R. M.; Caldwell, J. W.; Kollman, P. A.; Case, D. A. Development and testing of a general amber force field. J. Comput. Chem. 2004, 25, 1157-1174.

(54) Vymětal, J.; Vondrášek, J. Parametrization of 2, 2, 2trifluoroethanol based on the generalized AMBER force field provides realistic agreement between experimental and calculated properties of pure liquid as well as water-mixed solutions. J. Phys. Chem. B 2014, $118,10390-10404$.

(55) Gerig, J. T. Toward a molecular dynamics force field for simulations of $40 \%$ trifluoroethanol-water. J. Phys. Chem. B 2014, 118, $1471-1480$. 
(56) Robalo, J. R.; Huhmann, S.; Koksch, B.; Vila Verde, A. The multiple origins of the hydrophobicity of fluorinated apolar amino acids. Chem. 2017, 3, 881-897.

(57) Cieplak, P.; Cornell, W. D.; Bayly, C.; Kollman, P. A. Application of the multimolecule and multiconformational RESP methodology to biopolymers: Charge derivation for DNA, RNA, and proteins. J. Comput. Chem. 1995, 16, 1357-1377.

(58) Frisch, M. J.; Trucks, G. W.; Schlegel, H. B.; Scuseria, G. E.; Robb, M. A.; Cheeseman, J. R.; Montgomery, J. A., Jr.; Vreven, T.; Kudin, K. N.; Burant, J. C.; Millam, J. M.; Iyengar, S. S.; Tomasi, J.; Barone, V.; Mennucci, B.; Cossi, M.; Scalmani, G.; Rega, N.; Petersson, G. A.; Nakatsuji, H.; Hada, M.; Ehara, M.; Toyota, K.; Fukuda, R.; Hasegawa, J.; Ishida, M.; Nakajima, T.; Honda, Y.; Kitao, O.; Nakai, H.; Klene, M.; Li, X.; Knox, J. E.; Hratchian, H. P.; Cross, J. B.; Bakken, V.; Adamo, C.; Jaramillo, J.; Gomperts, R.; Stratmann, R. E.; Yazyev, O.; Austin, A. J.; Cammi, R.; Pomelli, C.; Ochterski, J. W.; Ayala, P. Y.; Morokuma, K.; Voth, G. A.; Salvador, P.; Dannenberg, J. J.; Zakrzewski, V. G.; Dapprich, S.; Daniels, A. D.; Strain, M. C.; Farkas, O.; Malick, D. K.; Rabuck, A. D.; Raghavachari, K.; Foresman, J. B.; Ortiz, J. V.; Cui, Q.; Baboul, A. G.; Clifford, S.; Cioslowski, J.; Stefanov, B. B.; Liu, G.; Liashenko, A.; Piskorz, P.; Komaromi, I.; Martin, R. L.; Fox, D. J.; Keith, T.; Al-Laham, M. A.; Peng, C. Y.; Nanayakkara, A.; Challacombe, M.; Gill, P. M. W.; Johnson, B.; Chen, W.; Wong, M. W.; Gonzalez, C.; Pople, J. A. Gaussian 03, revision E.01; Gaussian, Inc.: Wallingford, CT, 2004.

(59) Wang, J.; Wang, W.; Kollman, P. A.; Case, D. A. Automatic atom type and bond type perception in molecular mechanical calculations. J. Mol. Graphics Modell. 2006, 25, 247-260.

(60) Case, D. A.; Babin, V.; Berryman, J. T.; Betz, R. M.; Cai, Q.; Cerutti, D. S.; Cheatham, T. E., III; Darden, T. A.; Duke, R. E.; Gohlke, H.; Goetz, A. W.; Gusarov, S.; Homeyer, N.; Janowski, P.; Kaus, J.; Kolossváry, I.; Kovalenko, A.; Lee, T. S.; LeGrand, S.; Luchko, T.; Luo, R.; Madej, B.; Merz, K. M.; Paesani, F.; Roe, D. R.; Roitberg, A.; Sagui, C.; Salomon-Ferrer, R.; Seabra, G.; Simmerling, C. L.; Smith, W.; Swails, J.; Walker, R. C.; Wang, J.; Wolf, R. M.; Wu, X.; Kollman, P. A. AMBER 14;University of California, San Francisco, 2014.

(61) Berendsen, H.; van der Spoel, D.; van Drunen, R. GROMACS: A message-passing parallel molecular dynamics implementation. Comput. Phys. Commun. 1995, 91, 43-56.

(62) Lindahl, E.; Hess, B.; van der Spoel, D. GROMACS 3.0: a package for molecular simulation and trajectory analysis. J. Mol. Model. 2001, 7, 306-317.

(63) Van Der Spoel, D.; Lindahl, E.; Hess, B.; Groenhof, G.; Mark, A. E.; Berendsen, H. J. C. GROMACS: Fast, flexible, and free. J. Comput. Chem. 2005, 26, 1701-1718.

(64) Hess, B.; Kutzner, C.; Van Der Spoel, D.; Lindahl, E. GROMACS 4: Algorithms for highly efficient, load-balanced, and scalable molecular simulation. J. Chem. Theory Comput. 2008, 4, 435447.

(65) Pronk, S.; Páll, S.; Schulz, R.; Larsson, P.; Bjelkmar, P.; Apostolov, R.; Shirts, M. R.; Smith, J. C.; Kasson, P. M.; van der Spoel, D.; Hess, B.; Lindahl, E. GROMACS 4.5: A high-throughput and highly parallel open source molecular simulation toolkit. Bioinformatics 2013, 29, 845-854.

(66) Páll, S.; Abraham, M. J.; Kutzner, C.; Hess, B.; Lindahl, E. In International Conference on Exascale Applications and Software (EASC 2014); Lecture Notes in Computer Science; Markidis, S., Laure, E., Eds.; Springer International Publishing: Cham, 2015; Vol. 8759, pp 3-27.

(67) Abraham, M. J.; Murtola, T.; Schulz, R.; Páll, S.; Smith, J. C.; Hess, B.; Lindahl, E. GROMACS: High performance molecular simulations through multi-level parallelism from laptops to supercomputers. SoftwareX 2015, 1, 19-25.

(68) Sousa da Silva, A. W.; Vranken, W. F. ACPYPE - Antechamber python parser interface. BMC Res. Notes 2012, 5, 367.

(69) Hess, B.; Bekker, H.; Berendsen, H. J. C.; Fraaije, J. G. E. M. LINCS: A linear constraint solver for molecular simulations. J. Comput. Chem. 1997, 18, 1463-1472.
(70) Essmann, U.; Perera, L.; Berkowitz, M. L.; Darden, T.; Lee, H.; Pedersen, L. G. A smooth particle mesh Ewald method. J. Chem. Phys. 1995, 103, 8577-8593.

(71) Humphrey, W.; Dalke, A.; Schulten, K. VMD: visual molecular dynamics. J. Mol. Graphics 1996, 14, 33-38.

(72) Jeziorski, B.; Moszynski, R.; Szalewicz, K. Perturbation theory approach to intermolecular potential energy surfaces of van der Waals complexes. Chem. Rev. 1994, 94, 1887-1930.

(73) Hohenstein, E. G.; Sherrill, C. D. Wavefunction methods for noncovalent interactions. Wiley Interdiscip. Rev. Comput. Mol. Sci. 2012, 2, 304-326.

(74) Parrish, R. M.; Burns, L. A.; Smith, D. G. A.; Simmonett, A. C.; DePrince, A. E.; Hohenstein, E. G.; Bozkaya, U.; Sokolov, A. Y.; Di Remigio, R.; Richard, R. M.; Gonthier, J. F.; James, A. M.; McAlexander, H. R.; Kumar, A.; Saitow, M.; Wang, X.; Pritchard, B. P.; Verma, P.; Schaefer, H. F.; Patkowski, K.; King, R. A.; Valeev, E. F.; Evangelista, F. A.; Turney, J. M.; Crawford, T. D.; Sherrill, C. D. Psi4 1.1: An open-source electronic structure program emphasizing automation, advanced libraries, and interoperability. J. Chem. Theory Comput. 2017, 13, 3185-3197.

(75) Dunning, T. H., Jr Gaussian basis sets for use in correlated molecular calculations. I. The atoms boron through neon and hydrogen. J. Chem. Phys. 1989, 90, 1007-1023.

(76) Kendall, R. A.; Dunning, T. H., Jr; Harrison, R. J. Electron affinities of the first-row atoms revisited. Systematic basis sets and wave functions. J. Chem. Phys. 1992, 96, 6796-6806.

(77) Weigend, F.; Köhn, A.; Hättig, C. Efficient use of the correlation consistent basis sets in resolution of the identity MP2 calculations. J. Chem. Phys. 2002, 116, 3175-3183.

(78) Weigend, F. A fully direct RI-HF algorithm: Implementation, optimised auxiliary basis sets, demonstration of accuracy and efficiency. Phys. Chem. Chem. Phys. 2002, 4, 4285-4291.

(79) Parker, T. M.; Burns, L. A.; Parrish, R. M.; Ryno, A. G.; Sherrill, C. D. Levels of symmetry adapted perturbation theory (SAPT) I. Efficiency and performance for interaction energies. J. Chem. Phys. 2014, 140, No. 094106.

(80) Parrish, R. M.; Hohenstein, E. G.; Sherrill, C. D. Tractability gains in symmetry-adapted perturbation theory including coupled double excitations: CCD+ ST (CCD) dispersion with natural orbital truncations. J. Chem. Phys. 2013, 139, 174102.

(81) Hohenstein, E. G.; Jaeger, H. M.; Carrell, E. J.; Tschumper, G. S.; Sherrill, C. D. Accurate interaction energies for problematic dispersion-bound complexes: homogeneous dimers of NCCN, P2, and PCCP. J. Chem. Theory Comput. 2011, 7, 2842-2851.

(82) Hohenstein, E. G.; Sherrill, C. D. Efficient evaluation of triple excitations in symmetry-adapted perturbation theory via second-order Møller-Plesset perturbation theory natural orbitals. J. Chem. Phys. 2010, 133, 104107.

(83) Hohenstein, E. G.; Sherrill, C. D. Density fitting and Cholesky decomposition approximations in symmetry-adapted perturbation theory: Implementation and application to probe the nature of $\pi-\pi$ interactions in linear acenes. J. Chem. Phys. 2010, 132, 184111.

(84) Hohenstein, E. G.; Sherrill, C. D. Density fitting of intramonomer correlation effects in symmetry-adapted perturbation theory. J. Chem. Phys. 2010, 133, No. 014101.

(85) Morawietz, T.; Marsalek, O.; Pattenaude, S. R.; Streacker, L. M.; Ben-Amotz, D.; Markland, T. E. The interplay of structure and dynamics in the Raman spectrum of liquid water over the full frequency and temperature range. J. Phys. Chem. Lett. 2018, 9, 851857.

(86) Wu, X.; Lu, W.; Streacker, L. M.; Ashbaugh, H. S.; Ben-Amotz, D. Methane hydration-shell structure and fragility. Angew. Chem., Int. Ed. 2018, 57, 15133-15137.

(87) Li, F.; Skinner, J. L. Infrared and Raman line shapes for ice Ih. II. $\mathrm{H}_{2} \mathrm{O}$ and $\mathrm{D}_{2} \mathrm{O}$. J. Chem. Phys. 2010, 133, 244504.

(88) Perttilä, M. Vibrational spectra and normal coordinate analysis of 2,2,2-trichloroethanol and 2,2,2-trifluoroethanol. Spectrochim. Acta, Part A 1979, 35, 585-592. 
(89) Fecko, C. J.; Eaves, J. D.; Loparo, J. J.; Tokmakoff, A.; Geissler, P. L. Ultrafast hydrogen-bond dynamics in the infrared spectroscopy of water. Science 2003, 301, 1698-1702.

(90) Hermansson, K. Blue-shifting hydrogen bonds. J. Phys. Chem. A 2002, 106, 4695-4702.

(91) Scheiner, S.; Kar, T. Red- versus blue-shifting hydrogen bonds: Are there fundamental distinctions? J. Phys. Chem. A 2002, 106, $1784-1789$.

(92) Robalo, J. R.; Vila Verde, A. Unexpected trends in the hydrophobicity of fluorinated amino acids reflect competing changes in polarity and conformation. Phys. Chem. Chem. Phys. 2019, 21, 2029-2038.

(93) Heger, M.; Scharge, T.; Suhm, M. A. From hydrogen bond donor to acceptor: The effect of ethanol fluorination on the first solvating water molecule. Phys. Chem. Chem. Phys. 2013, 15, 1606516073.

(94) Khaliullin, R. Z.; Kühne, T. D. Microscopic properties of liquid water from combined ab initio molecular dynamics and energy decomposition studies. Phys. Chem. Chem. Phys. 2013, 15, 1574615766 .

(95) Thomas, J.; Seifert, N. A.; Jäger, W.; Xu, Y. A direct link from the gas to the condensed phase: A rotational spectroscopic study of 2,2,2-trifluoroethanol trimers. Angew. Chem., Int. Ed. 2017, 56, 62896293.

(96) Haider, K.; Wickstrom, L.; Ramsey, S.; Gilson, M. K.; Kurtzman, T. Enthalpic breakdown of water structure on protein active-site surfaces. J. Phys. Chem. B 2016, 120, 8743-8756.

(97) Cahard, D.; Bizet, V. The influence of fluorine in asymmetric catalysis. Chem. Soc. Rev. 2014, 43, 135-147.

(98) Jung, Y.; Marcus, R. A. On the theory of organic catalysis "on water". J. Am. Chem. Soc. 2007, 129, 5492-5502.

(99) Cheng, Y. K.; Rossky, P. J. Surface topography dependence of biomolecular hydrophobic hydration. Nature 1998, 392, 696-699.

(100) Bandyopadhyay, S.; Chakraborty, S.; Bagchi, B. Secondary structure sensitivity of hydrogen bond lifetime dynamics in the protein hydration layer. J. Am. Chem. Soc. 2005, 127, 16660-16667.

(101) Heugen, U.; Schwaab, G.; Bruendermann, E.; Heyden, M.; Yu, X.; Leitner, D. M.; Havenith, M. Solute-induced retardation of water dynamics probed directly by terahertz spectroscopy. Proc. Natl. Acad. Sci. U. S. A. 2006, 103, 12301-12306.

(102) Sobolewski, E.; Makowski, M.; Czaplewski, C.; Liwo, A.; Ołdziej, S.; Scheraga, H. A. Potential of mean force of hydrophobic association: Dependence on solute size. J. Phys. Chem. B 2007, 111, 10765-10774.

(103) Laage, D.; Stirnemann, G.; Hynes, J. T. Why water reorientation slows without iceberg formation around hydrophobic solutes. J. Phys. Chem. B 2009, 113, 2428-2435.

(104) Makowski, M.; Czaplewski, C.; Liwo, A.; Scheraga, H. A. Potential of mean force of association of large hydrophobic particles: Toward the nanoscale limit. J. Phys. Chem. B 2010, 114, 993-1003.

(105) Stirnemann, G.; Castrillón, S. R.-V.; Hynes, J. T.; Rossky, P. J.; Debenedetti, P. G.; Laage, D. Non-monotonic dependence of water reorientation dynamics on surface hydrophilicity: Competing effects of the hydration structure and hydrogen-bond strength. Phys. Chem. Chem. Phys. 2011, 13, 19911-19917.

(106) Li, I. T. S.; Walker, G. C. Signature of hydrophobic hydration in a single polymer. Proc. Natl. Acad. Sci. U. S. A. 2011, 108, 1652716532 .

(107) Vila Verde, A.; Campen, R. K. Disaccharide topology induces slowdown in local water dynamics. J. Phys. Chem. B 2011, 115, 70697084.

(108) Lin, B.; Wong, K.-Y.; Hu, C.; Kokubo, H.; Pettitt, B. M. Fast calculations of electrostatic solvation free energy from reconstructed solvent density using proximal radial distribution functions. J. Phys. Chem. Lett. 2011, 2, 1626-1632.

(109) Snyder, P. W.; Mecinović, J.; Moustakas, D. T.; Thomas, S. W., III; Harder, M.; Mack, E. T.; Lockett, M. R.; Héroux, A.; Sherman, W.; Whitesides, G. M. Mechanism of the hydrophobic effect in the biomolecular recognition of arylsulfonamides by carbonic anhydrase. Proc. Natl. Acad. Sci. U. S. A. 2011, 108, 17889-17894.

(110) Patel, A. J.; Varilly, P.; Jamadagni, S. N.; Hagan, M. F.; Chandler, D.; Garde, S. Sitting at the edge: How biomolecules use hydrophobicity to tune their interactions and function. J. Phys. Chem. B 2012, 116, 2498-2503.

(111) Lockett, M. R.; Lange, H.; Breiten, B.; Heroux, A.; Sherman, W.; Rappoport, D.; Yau, P. O.; Snyder, P. W.; Whitesides, G. M. The binding of benzoarylsulfonamide ligands to human carbonic anhydrase is insensitive to formal fluorination of the ligand. Angew. Chem., Int. Ed. 2013, 52, 7714-7717.

(112) Breiten, B.; Lockett, M. R.; Sherman, W.; Fujita, S.; Al-Sayah, M.; Lange, H.; Bowers, C. M.; Heroux, A.; Krilov, G.; Whitesides, G. M. Water networks contribute to enthalpy/entropy compensation in protein-ligand binding. J. Am. Chem. Soc. 2013, 135, 15579-15584.

(113) Wilcox, D. S.; Rankin, B. M.; Ben-Amotz, D. Distinguishing aggregation from random mixing in aqueous t-butyl alcohol solutions. Faraday Discuss. 2014, 167, 177-190.

(114) Snyder, P. W.; Lockett, M. R.; Moustakas, D. T.; Whitesides, G. M. Is it the shape of the cavity, or the shape of the water in the cavity? Eur. Phys. J.: Spec. Top. 2014, 223, 853-891.

(115) Dinpajooh, M.; Matyushov, D. V. Interfacial structural transition in hydration shells of a polarizable solute. Phys. Rev. Lett. 2015, 114, 207801.

(116) Weiss, R. G.; Heyden, M.; Dzubiella, J. Curvature dependence of hydrophobic hydration dynamics. Phys. Rev. Lett. 2015, 114, 187802.

(117) Ou, S.-C.; Pettitt, B. M. Solute-solvent energetics based on proximal distribution functions. J. Phys. Chem. B 2016, 120, 82308237.

(118) Stillinger, F. H. Structure in aqueous solutions of nonpolar solutes from the standpoint of scaled-particle theory. J. Solution Chem. 1973, 2, 141-158.

(119) Lum, K.; Chandler, D.; Weeks, J. D. Hydrophobicity at small and large length scales. J. Phys. Chem. B 1999, 103, 4570-4577. 